\title{
MASTER
}

Copy № $\quad 19$

APAE Memo - 316

AEC Rescarch and

Development Report

UC-81, Reactors-Power

[Special Distribution]

\section{selection of core design no. 1 \\ for type 5 replacement cores \\ for SM-1 and SM-1A}

Contract No. AT[30-1]-2639

with U. S. Atomic Energy Commission

New York Operations Office

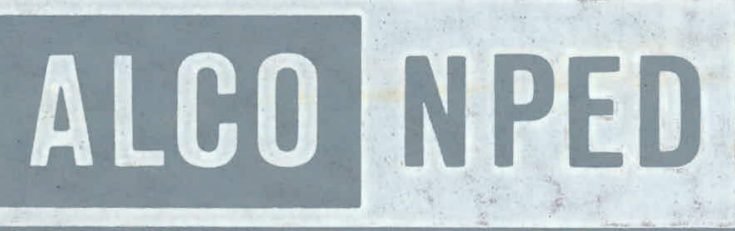

ALCO PRODUCTS, INC. NUCLEAR POWER ENGINEERING DEPARTMENT 


\section{DISCLAIMER}

This report was prepared as an account of work sponsored by an agency of the United States Government. Neither the United States Government nor any agency Thereof, nor any of their employees, makes any warranty, express or implied, or assumes any legal liability or responsibility for the accuracy, completeness, or usefulness of any information, apparatus, product, or process disclosed, or represents that its use would not infringe privately owned rights. Reference herein to any specific commercial product, process, or service by trade name, trademark, manufacturer, or otherwise does not necessarily constitute or imply its endorsement, recommendation, or favoring by the United States Government or any agency thereof. The views and opinions of authors expressed herein do not necessarily state or reflect those of the United States Government or any agency thereof. 


\section{DISCLAIMER}

Portions of this document may be illegible in electronic image products. Images are produced from the best available original document. 
APAE Memo-316

AEC Reserach and

Development Report.

UC-81, Reactors, Power

(Special Distribution)

SELLETION OF CORE DESIGN NO.I

FOR TYPE 5 REPLACEMENT CORES IN SM-1 AND SM-1A

\author{
By \\ S.L。Davidson \\ S. Paluszkiewicz
}

Approved by:

E.W. Schrader, Acting Project Engineer

Issued: July. 3, 1962

Contract No.AT(30-1)-2639

with U.S.Atomic Energy Commission

New York Operations Office

ALCO PRODUCTS; INCORPORATED

Nuclear Power Engineering Department

Post Office Box 414

Schenectady: 1, New York 
AEC LEGAL NOTICE

This report was prepared as an account of Government sponsored work. Neither the United States, nor the Commission, nor any person acting on behalf of the Commission:

A. Makes any warranty or representation, expressed or implied, with respect to the accuracy, completeness, or usefulness of the information contained in this report, or that the use of any information, apparatus, method, or process disclosed in this report may not infringe privately owned rights:

B. Assumes any liabilities with respect to the use of, or for damages resulting from the use of any information, apparatus, method, or process disclosed in this report.

As used in the above, "person acting on behalf of the Commission" includes any employee or contractor of the Commission, or employee of such contractor, to the extent that such employee or contractor of the Commission, or employee of such contractor prepares, disseminates, or provides access to, any information pursuant to his employment or contract with the Commission, or his employment with such contractor.

\section{ALCO LEGAL NOTICE}

This report was prepared by Alco Products, Incorporated in the course of work under, or in connection with, Contract No. AT (30-1)-2639, issued by U.S.Atomic Energy Commission, NYOO; and subject only to the rights of the United States, under the provisions of this contract, Alco Products, Incorporated makes no warranty or representation, express or implied, and shall have no liability with respect to this report or any of its contents or with respect to the use thereof or with respect to whether any such use will infringe the rights of others. 


\section{DISTRIBUTION}

External

Copies

I - 2 New York Operations Office

U . S.Atomic Energy Commission

376 Hudson Street

New York 14, New York

Attẹntion: I. M. Adler

New York Operations Office

$\mathrm{U}$. S.Atomic Energy Commission

376 Hudson Street

New York 14, New York

Attention: Library

4 - 6 U. S. Atomic Energy Commission

Washington $25, \mathrm{D}$ 。C 。

Attention: Chief, Water Systems Project.

Branch: (Army Reactorș)

Division of Reactor Development

Mail Station F-311

7. U. S.Atomic Energy Commission

Wa shington $25, \mathrm{D} . \mathrm{C}$.

Attention: Chief Evaluation and

Planning Branch

Civilian Reactors

Div. of Reactor Development

Mail Station F-311

8 U.S.Atomic Energy Commission

Chief, New York Patent Group

Brookhaven National Laboratory.

Upton, New York

Attention: Harman Potter

9 Idaho Nuclear Power Field Office

P.O. Box 2108

Idaho Falls $s_{\text {o. }}$ Idaho 


\section{DISTRIBUTION (CONT'D)}

External

Copies.

10

U. S.Atomic Energy Commission

Reports and Statistics Branch

Division of Reactor Development

Wa shington 25. D.C.

I1 - 12 Office of the Chief of Engineers

Department of the Army

Building $\mathrm{T}-7$

Washington 25, D.C.

Attention: Chief, Projects Branch

Nuclear Power Division

$\therefore 13$ - 15 Nuclear Power Field Office

U. S. Army Engineer Reactors Group

Fort Belvoir, Virginia

Attention: Chief, Nuclear Power

Field Office

I6 . Nuclear Power Field Office

U. S. Army Engineer Reactors Group

Fort Belvoir, Virginia

Attention: O.I.C. SM-1

17 Chief, U.S.Army Reactors Group

Fort Greely, Alaska

APO 733

Seattle, Washington

Attention: O.I.C. SM-1A

18 Commanding Officer

U.S. Army Polar Research

and Development Center

Fort Belvoir, Virginia

Attention: Nuclear Power Officer

$19-21$ Office of Technical Information Extension

P.O. Box 62

Oak Ridge, Tennessee 


\section{DISTRIBUTION (CONT'D)}

External

Copies

22

Union Carbide Nuclear Corporation

Oak Ridge National Laberatory

Y-12 Building 9704-1

P.O. Box " $Y$ "

Oak Ridge, Tennessee

Attention: L. D. Schăfier

23 The Martin Company

P.O.Box 5042

Middle River, Maryland

Attention: AEC Contract Document Custodian

$24-25 \quad$ Combustion Engineering, Incorporated

Nuclear Division

Prospect Hill Road

Windsor, Connecticut

Attention: Mr.J.B. Anderson

Internal

Copies

26

27

28

29

30

31

32

33

34

35

36: -40
K. Kasschau

J. G. Gallagher

$J$. F . Haines

P. E. Bobe

W. T. Williams

S. L. Davidson

S. Paluszkiewicz

B: E. Fried

F. T. Matthews

R. E. Neville

NPED Vault 


\section{THIS PAGE}

WAS INTENTIONALLY

LEFT BLANK 
Nuclear and thermal analyses were performed to determine: the characteristics of the Type 5 core in the SM-I and SM-1A reactor plants as a function of geometry and composition. The following nuclear properties were investigated: core energy release, maximum midlife reactivity, average fuel burnup fraction, B-10 reactivity coefficient, and power distribution.

Thermal parameter surveys determined the effects of channel thickness and power distribution upon the DNBR, nominal and hot channel thermal performance and fuel plate: thermal stress. From the nuclear and thermal analyses, a Type 5 core reference design was selected with fuel plates of 70 -mil plate thickness, 7-mil clad thickness, and $38 \mathrm{w} / \circ \mathrm{UO}_{2}$ in the matrix, having initial core loading of $108 \mathrm{Kg}: \mathrm{U}-235$ and $260 \mathrm{gm} \mathrm{B}-10$ 。 


\section{THIS PAGE}

WAS INTENTIONALLY

LEFT BLANK 


\section{TABLE OF CONTENTS}

$\underline{\text { Page }}$

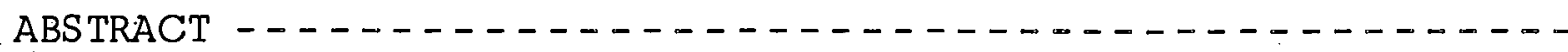

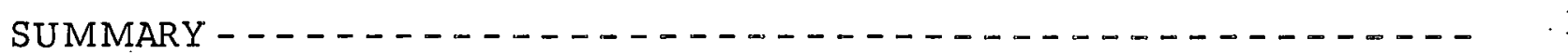

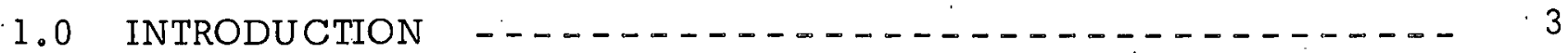

2.0 DESCRIPTION OF TYPE 5 CORE $\ldots \ldots \ldots \ldots \ldots \ldots \ldots \ldots \ldots \ldots \ldots \ldots \ldots \ldots$

2. I Core Geometry and U-235 Lnadings _- _ $\ldots \ldots \ldots \ldots \ldots$

3.0 NUCLEAR ANALYSIS _... $\ldots \ldots \ldots, \ldots \ldots$

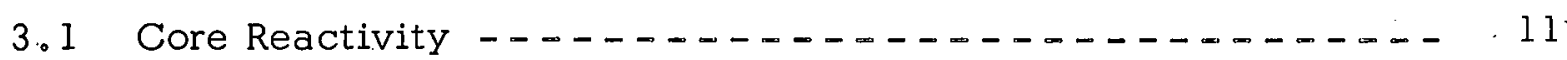

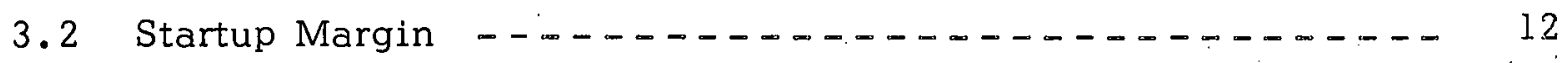

3.2 .1 . Worth of Substitution Effect. $\ldots \ldots \ldots$

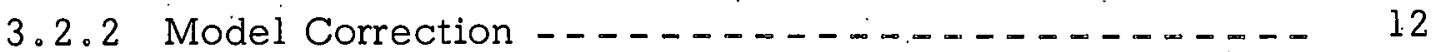

3.2 .3 Worth of Equilibrium Xenon _.............. 12

3.3 Determination of Initial B-10 Loadings $\ldots \ldots \ldots \ldots$

3.4 Core Energy Release _.

3.4.1 Uniform Burnup- $\ldots \ldots \ldots-\ldots \ldots \ldots$

3.4.2 Non-Uniform Burnup _.............. 15

3.4.3.. Use of Calculational Design Techṇique - - - - - - 17

3.5 Maximum Excess Reactivity _- $\ldots \ldots \ldots \ldots \ldots$

3.6 Average Fuel Burnup Fraction _ $\ldots \ldots \ldots \ldots$

3.7: Worth of B-10 at Start-of-Life

3.8 : Preliminary Power Distributions and Peaking Factors - - - - - 25

3.8.1 Axial Power Distribution _.

3.8 .1 .1 Calculation of $\Sigma_{p}$ for Use in WINDOWSHADE

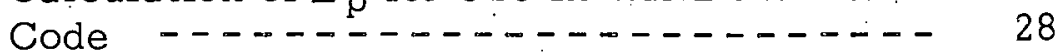

3.8.2 Radial Power Peaking Factors $\ldots \ldots \ldots-\ldots$ 


\section{TABLE OF CONTENTS (CONT'D)}

Page

4.0 THERMAL-HYDRAULIC ANALYSIS $-\ldots \ldots-\ldots$

4.I Hot Channel Analysis - - - - - - - - - - - - - - - - - - 31

4.2 Thermal Stress Analysis for Type 5 Fuel Plates - - - - - -

4.2.I Stress Induced by Temperature Variation Across

Thickness of Plate - - - - - - - - - - -

4.2.2 Stress Induced by Side Plate Restraint-- - - - - - - 40

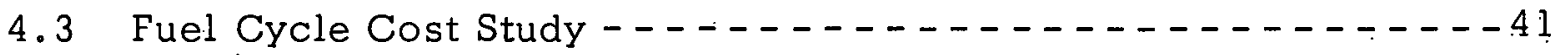

5.0 SELECTION OF REFERENCE DESIGN NO. 1 - $-\ldots-\ldots$

5.1 Thermal Criteria - $-\ldots \ldots-\ldots-\ldots-\ldots$

5.2 Nuclear Criteria $\ldots \ldots-\ldots-\ldots-\ldots-\ldots-\ldots$

5.3 Metallurgical Criteria - - - - - - - - - - - - - - - - - - 48

5.4 Thermal Stress Criteria - - - - - - - - - - - - - - - - - - - - 48

5.5 Economic Criteria - - - - - - - - - - - - - - - - - - - 48

5.6 Nuclear and Thermal Design Data $-\cdots--------\cdots----48$

6.0 NUCLEAR ANALYSIS FOR SMALL-SIZE CORE $-\ldots-\cdots$

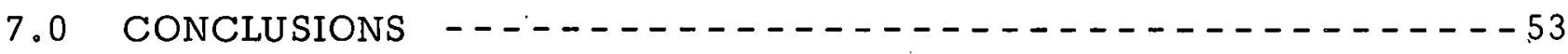

8.0 RECOMMENDATIONS AND FUTURE WORK $\ldots \ldots-\ldots$

9.0 REF ERENCES - - - - -

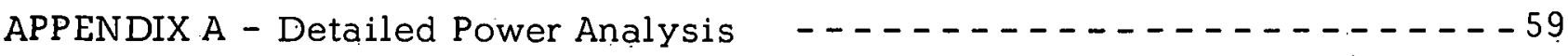

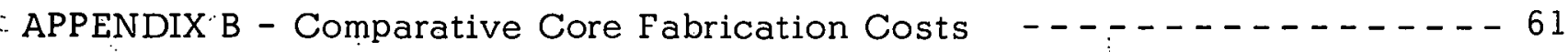




\section{LIST OF FIGURES}

Figure

Title

Page

I SM-I Core Layout

SM-1A. Core Layoul

3 Subdivision of a Stationary Fuel Element

Subdivision of a Control Rod Fuel Element

Initial U-235 Core Loading Vs Plate Thisknoc for Tỵpe 5 Core $\left(35 \mathrm{w} / \mathrm{OUO}_{2}\right)$

6 Initial U-235 Core Loading Vs Plate Thickness for Type 5 Core $\left(40 \mathrm{w} / \mathrm{UO}_{2}\right)$

7 Initial U-235 Core Loading Vs Plate Thickness for Tỵpe 5 ,Core (45 w/o $\mathrm{UO}_{2}$ )

8 Type 5 Core。 Reactivity Vs Burnup

9 SM-2 Core I, Type 3.;: Reactivity Change

(Non-Uniform Minus Uniform Burnup) Vs Burnup

10 Three-Factor. Box Design

11 Energy Release Vs Plate Thickness for Type 5 Core (45 Fuel Elements)

12 Energy Release Vs Plate Thickness for Type 5 Core (45 Fuel Elements)

13 Energy Release Vs Plate Thickness for Type 5 Core (45 Fuel Elements)

14 Maximum Midlife Reactivity Vs Plate Thickness for Type 5 Core

15 Relative Axial Power Distribution - Type 5 Elements in SM-1 Array

I6 Minimum DNBR Vs Plate Thickness - SM-1 Type 5

Core, 10.77 Miw

17

Minimum DNBR Vs Plate Thickness - SM-1A Type 5 Core, $20 \mathrm{Mw}$ 


\section{LIST OF FIGURES (CONT'D)}

Figure

Title.

Page

18 Àverage Pressure Drop Vs Plate Thickness; SM-1

Type 5 Core, 10.77 Mw

19 Average Pressure Drop Vs Plate Thickness, SM-1A

Tỵpe 5 Core, . $20 \mathrm{Mw}$

20 Type 5 Core Pump Operating Curves for SM-1A

Mechanical Seal Pump

21 Type 5 Cores Thermal Stress Vs Heatl Flux

22 Total Cost Vs Initial Load for Type 5 Core (45 Fuel Elements)

23 Total Cost Vs Initial Load for Type 5 Core

: (45 Fuel Elements)

24 Total Cost Vs Initial Load for Type 5 Core (45 Fuel Elements)

25 Small-Size Type 5 Reference Design 
$\underline{\text { Table }}$

Titile

Page

I Reflector Savings and Bucklings for Type 5 Core

2 Xenon Parameters for Type 5 Core, $440^{\circ} \mathrm{F}$

14

3 Nuclear Properties of 15 Type 5 Core Configurations

1 Rodiál Puwer Generation Factors for Type 5 Core in $\mathrm{SM}-1$ and SM-1A Arrays

5. Nuclear Characteristics of Type 5 Reference

Design in SM-1. Array

6 :Preliminary Thermal and Hydraulic Design. Data for Type 5 Cores 


\section{SUMMARY}

Nuclear and thermal properties of the Type 5 core in the SM-1 and SM-1A reactor plants were determined.for the following: variables: plate thickness (50-100 mils), clad thickness (5-10 mils), and w/o UO 2 in the matrix (35-45\%). Core energy release: was predicted by calculations of the Type 5 cores, applying reactivity: correction factors obtained from the differences between the uniform and non-uniform burnup behaviors of the SM-2 Core I. (1) Core reactivities were calculated by the equivalent bare model, employing modified two-group theory. Preliminary power distributions and peaking factors were obtained from diffusion theory calculations by applying correction factors obtained from the detailed power analysis of the Type 3 core ${ }^{(2)}$ in the SM-1 and SM-1A core arrays.

Hot channels. were established and analyzed for the most critical elements in the SM-l and SM-lA cores. Primary loop pressure drops were evaluated for various plate thicknesses. Thermal stress surveys were conducted to determine the thermal stress induced in the plate. Economic studies were performed to determine the reductions in fuel cycle costs as a result of the increased core life obtained by use of the thicker, more heavily, loaded Type 5 fuel plates.

On the basis of these analyses, a Type 5 reference design. was selected having a 70-mil plate, 7-mil clad, and $38 \mathrm{w} / 0 \mathrm{UO}_{2}$ in the matrix. The initial. $\mathrm{U}-235$ and $\mathrm{B}-10$ loading of the reference design were calculated to be $108 \mathrm{~kg}$ and $260 \mathrm{gm}$, respectively, yielding a core energy relea se of $108 \mathrm{MWYR}$ :

Small-size cores were studied utilizing the Type 5 reference fuel elements to determine their feasibility from the standpoint of core energy release. Cores consisting of $4 \times 4$ and $5 \times 5$ arrays, containing no B-10, appear to be feasible。 


\section{THIS PAGE}

WAS INTENTIONALLY

LEFT BLANK 


\subsection{INTRODUCTION}

In. support of the Army-Ten Year Core Development Program, nuclear and thermal studies were performed for Type 5 replacement cores.(21) At the present time, the Type 5 elements are the next developmental step after use of the Type 3 elements. This program was undertaken to establish the dependence of the core characteristics with variation of important physical parameters and permit a reference design to be selected.

This report was prepared undcr Subtask 3.7 of the 1 Y 1962 Program for Engineering Support and Development of Army Pressurized Water Reactor Plants: (21) 


\section{THIS PAGE}

WAS INTENTIONALLY

LEFT BLANK 


\subsection{DESCRIPTION OF TYPE 5 CORE}

The Type 5 core is envisaged as a pressurized water reactor suitable for operation in the $S M-1(3) S M-1 A,(4)$ and $P M-2 A$ reactor plants. The $S M-1$ and SM-IA core arrays are presented.in. Fig. I and 2, respectively; Each core consists of a $7 \times 7$ array of 38 , fixed and 7 control rod fuel elements with the four corner elements missing. The fuel elements consist of fuel plates containing highly enriched uranium dispersed in a stainless steel matrix clad with stạinless steel. The fixed fuel elements contain 18 fuel bearing plates, whereas: the control rod fuel elements contain 16 plates. The number of fuel plates per element was made the same as in the SM-l(3) and SM-2(5) cores, since a greater number of fuel plates would necessarily yield higher power peaking factors for the highly. loaded Type 5 core.

The SM-1 plant operates at a thermal power level of $10 \mathrm{Mw}$; the SM-1A operates at $20 \mathrm{MW}$. Because the SM-1 and SM-1A have.a lower thermal margin than the PM-2A, no analyses. were performed for a Type $5 \mathrm{PM}-2 \mathrm{~A}$ core.

\subsection{CORE GEOMETRY AND U-235 LOADINGS}

The fixed and control rod fuel elements of the Type 5 core are shown in Fig. 3 and 4 , respectively. Nuclear and thermal analyses were performed for the following range of variables: plate thickness, 50-100 mils; clad thickness, 5-10 mils; and $\mathrm{w} / \mathrm{O} \mathrm{U \odot}_{2}$ in the matrix, 35-45\%. The fuel cell size was 2.937 .5 x $2.9375 \times 22$ in。, while: the side plate thickness was 0.04 in. All other fuel element properties were taken to be the same äs those of the SM-2 Core. I(5) fuel elements.

Figures 5,6 , and 7 show the variation of initial U-235 loading for the Type 5 core: (38 fixed plus 7 control rod fuel elements) with plate: thickness。 parametric in clad thickness and $\mathrm{w} / \mathrm{OUO}_{2}$. A void volume fraction of $5 \%$ in the matrix. was assumed, as metallurgically determined for the SM-2 reference fuel elements.(6) The regular densities, $i_{0} e_{0}, \mathrm{gm} / \mathrm{cm}^{3}$, of $\mathrm{UO}_{2}$ and stainless steel, were taken to be 10.70 and 7.85 , respectively. (5) 
(D)

LOG N CHAMBER
(E)

SAFETY CHAMBER 20
(C)

SAFETY

CHAMBER I

(B)

$\mathrm{BF}_{3}$ COUNTER

STARTUP SOURCE

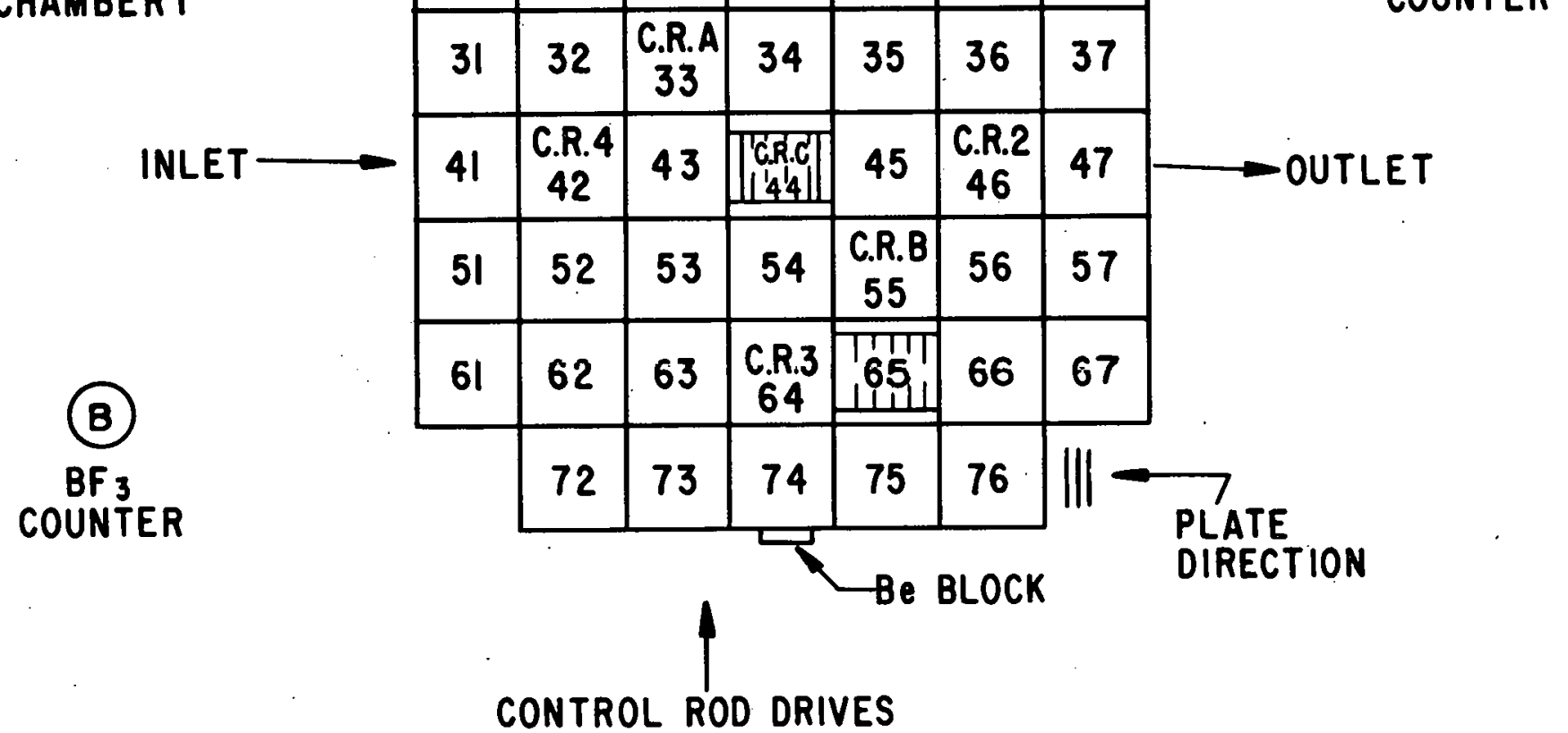




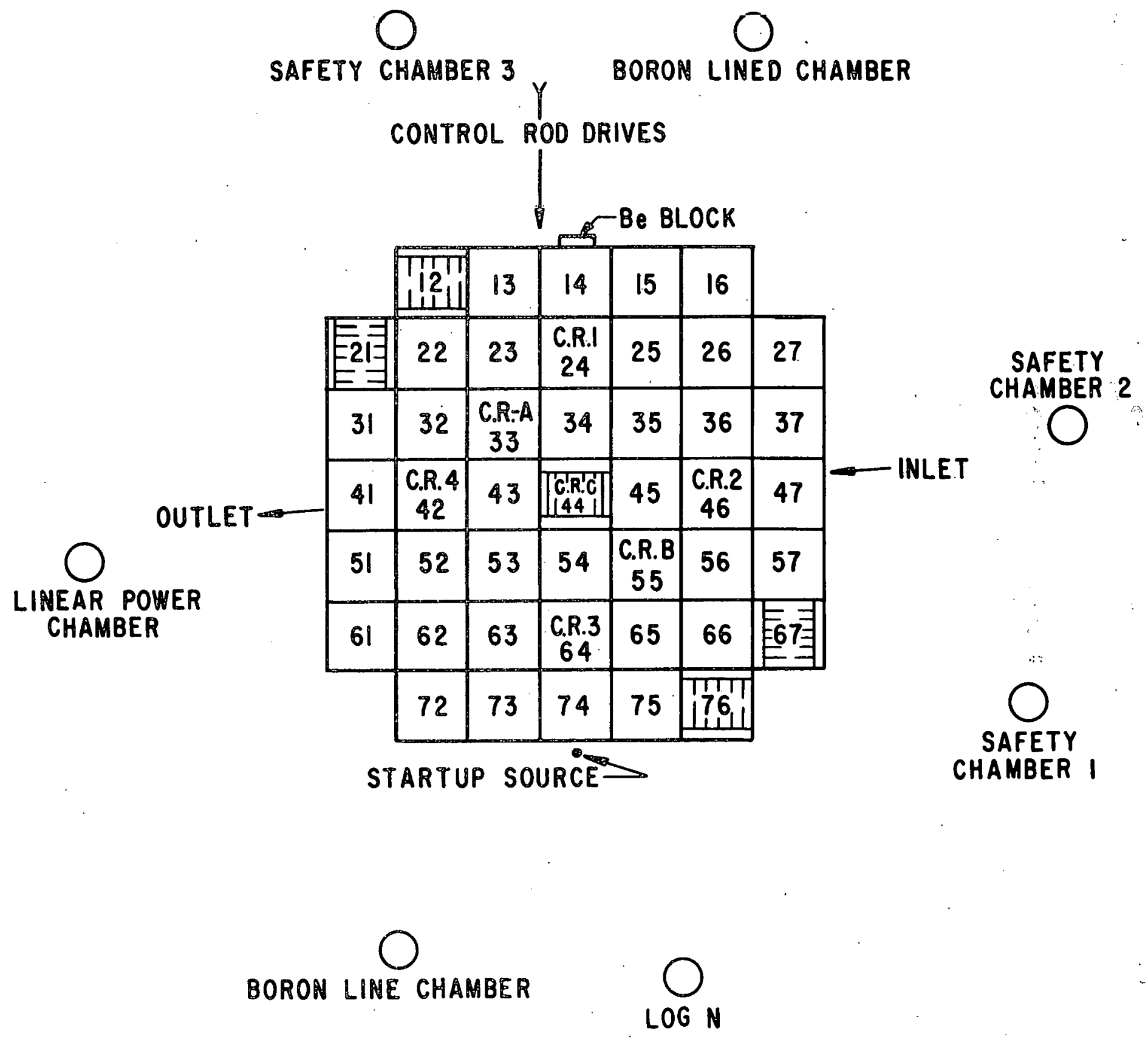

Figure 2. SM-1A Core Layout 


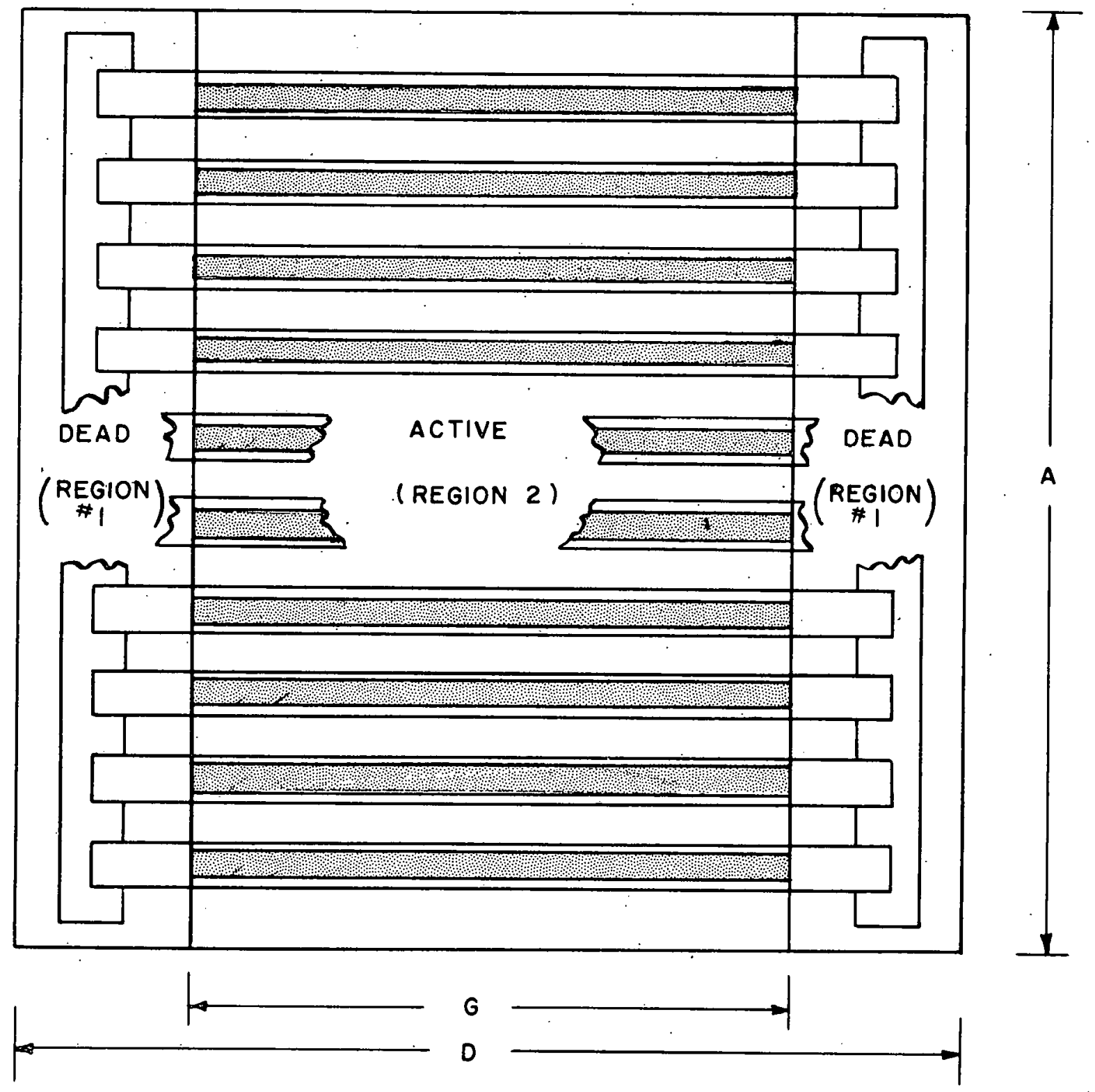

Figure 3. Subdivision of a Stationary Fuel Element 


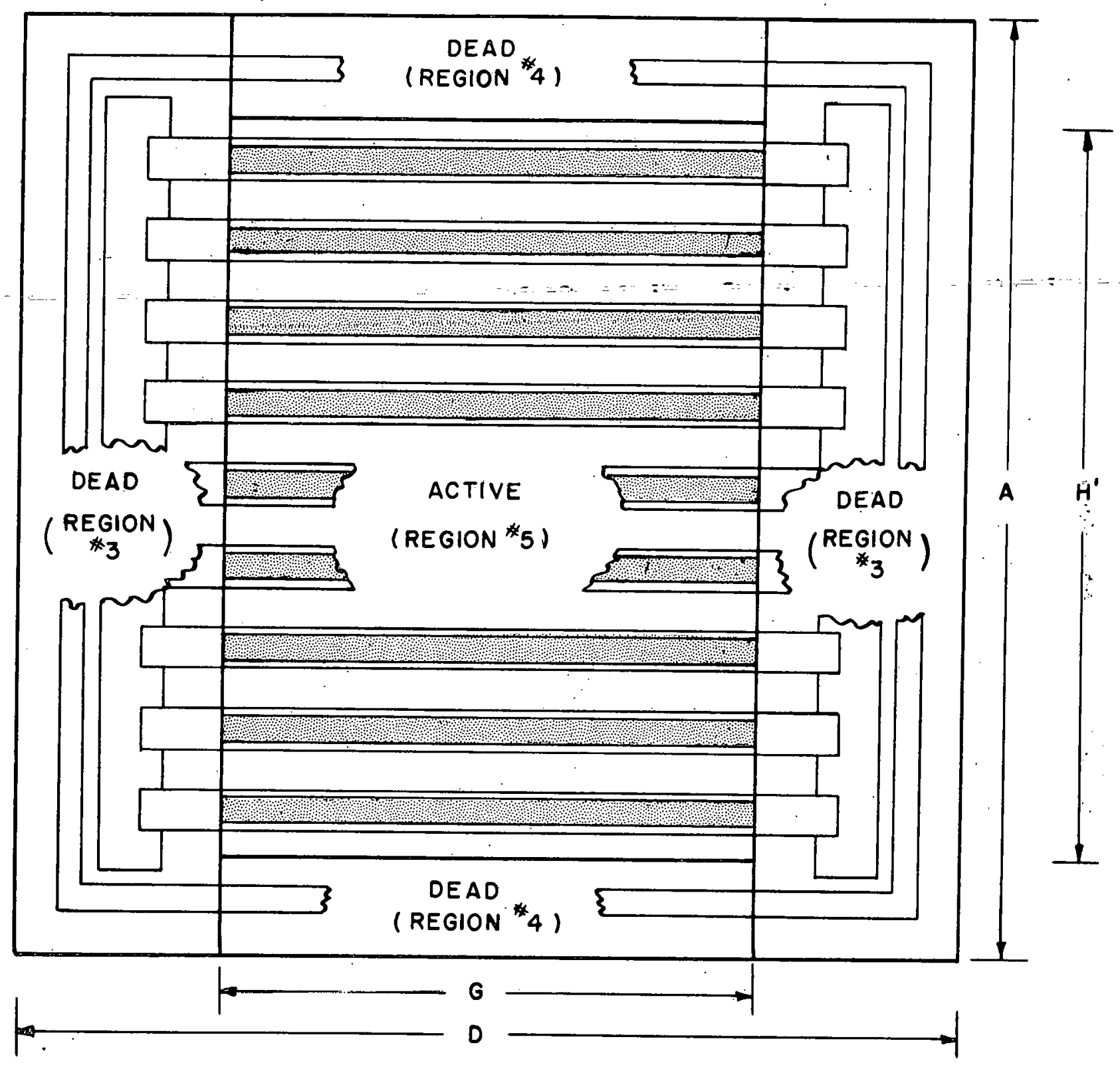

Figure 4. Subdivision of a Control Rod Fuel Element 


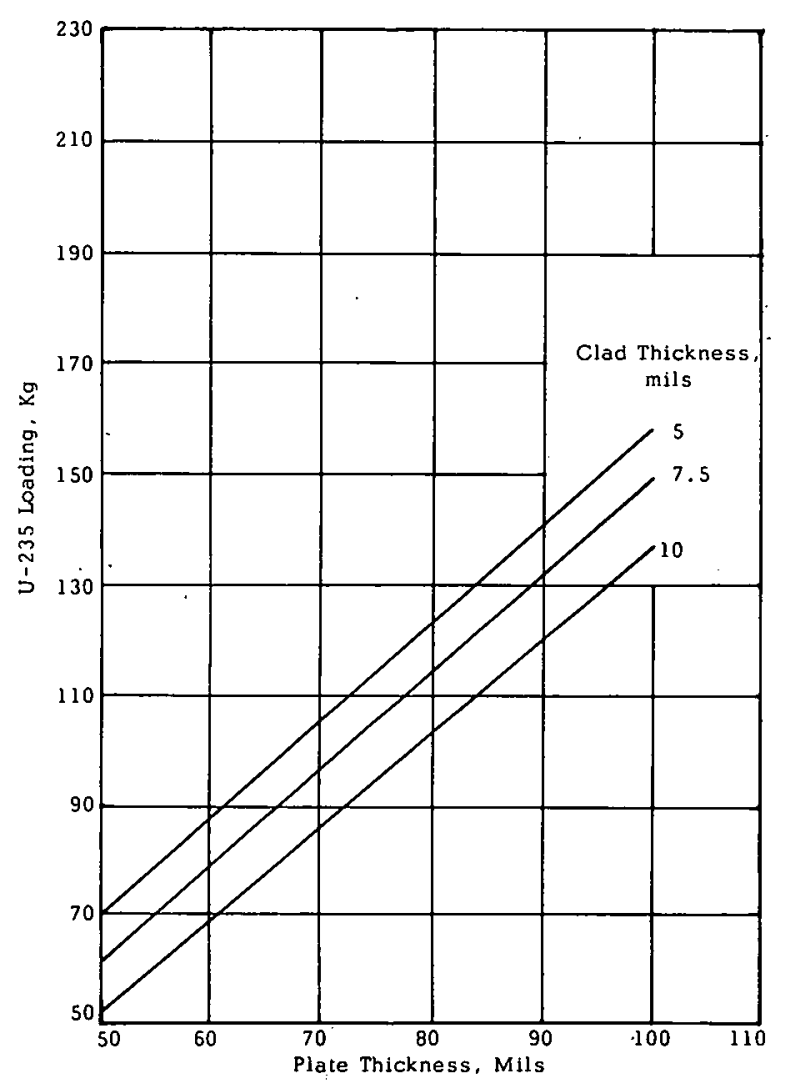

Figure 5. Initial U-235 Core Loading Vs Plate Thickness for Type 5 Core $\left(35 \mathrm{w} / \mathrm{o} \mathrm{UO}_{2}\right)$
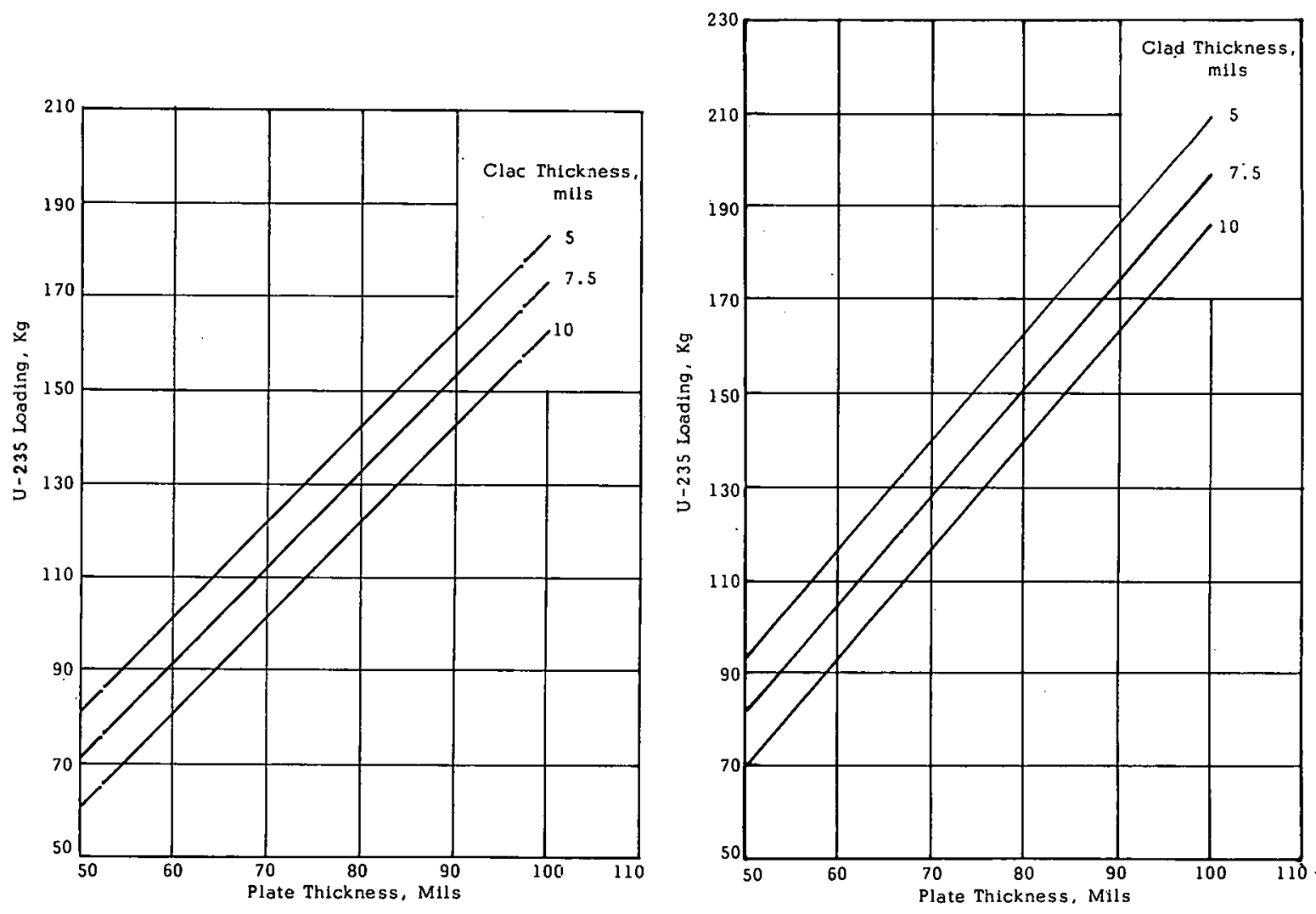

Figure 6. Initial U-235 Core Loading figure 7. Initial U-235 Core Loading Vs Plate Thickness for Type 5 Core $\left(40 \mathrm{w} / \mathrm{O} \mathrm{UO}_{2}\right)$ 5 Core $\left(45 \mathrm{w} / \mathrm{o} \mathrm{UO}_{2}\right)$ 


\subsection{NUCLEAR ANALYSIS}

Nuclear analysis. was performed for the Type 5 core to predict core energy release, maximum midlife reactivity, average fuel burnup. fraction, B-10 reactivity coefficient, power distribution and peaking factors.

\section{I CORE REACTIVITY}

Core reactivities of the Type 5 core were calculated by use of the equivalent bare model, (7) employing modified two-group theory, as presented in Eq。(1):

$$
K_{\text {eff }}=\frac{P K_{t h}}{\left(1+\tau B^{2}\right)\left(1+L^{2} B^{2}\right)}+\frac{K_{f}(1-P)}{1+\tau B^{2}}
$$

Fast nuclear constants were obtained by use of the MUFT-III, (8) IBM 650 machine code, with the $\mathrm{P}-1$ slowing-down approximation. The lower limits of the fast group were taken as $0.196 \mathrm{ev}$ at $68^{\circ} \mathrm{F}$ (cold and $0.248 \mathrm{ev}$ at $440^{\circ} \mathrm{F}$. Choice of cutoff energy: has been shown to have little effect on: $k_{\text {eff }}$ (9) Thermal nuclear constants were calculated by the two-dimensional P-3 ${ }^{\circ}(10)$ IBM 650 code, employing microscopic cross sections averaged over a hardened MaxwellBoltzmann neutron distribution.

The total buckling. $\mathrm{B}^{2}$, was calculated by use of $E q_{\text {。 }}$ (2), treating the Type 5. core as a bare cylinder with an as sociated reflector savings:

$$
B^{2}=B_{z}^{2}+\dot{B}_{r}^{2}=\left(\frac{\pi}{H+2 S_{z}}\right)^{2}+\left(\frac{2.405}{R+S_{r}}\right)^{2}
$$

Reflector savings obtained for the SM-1 Core $I_{0}(11)$ an APPR-type core composed of 45 fuel elements, were used for the analysis of the Type 5 core. The reflector savings and associated bucklings are presented in Table 1 .

TABLE 1.

\begin{tabular}{|c|c|c|c|c|c|}
\hline Temperature & $\begin{array}{l}\text { Axial } \\
\text { Reflector } \\
\text { Savings, } \\
\mathrm{S}_{z}, \mathrm{Cm}\end{array}$ & $\begin{array}{l}\text { Radial } \\
\text { Reflector } \\
\text { Savings } \\
\mathrm{S}_{\mathrm{r}}, \mathrm{cm}\end{array}$ & $\begin{array}{l}\text { Axial } \\
\text { Buckling } \\
\mathrm{B}_{\mathrm{z}}{ }^{2} \\
\mathrm{~cm}^{-2}\end{array}$ & $\begin{array}{l}\text { Radial } \\
\text { Buckling } \\
\mathrm{Br}^{2} \text { ' } \\
\mathrm{cm}^{-2}\end{array}$ & $\begin{array}{l}\text { Total } \\
\text { Buckling } \\
\mathrm{B}^{2} \\
\mathrm{Cm}^{-2}\end{array}$ \\
\hline $\operatorname{Cold}\left(68^{\circ} \mathrm{F}\right)$ & 5.11 & 6.18 & 0.002259 & 0.004895 & 0.007154 \\
\hline Hot $\left(440^{\circ} \mathrm{F}\right)$ & 6.10 & 7.80 & 0.002129 & 0.004465 & 006594 \\
\hline
\end{tabular}

REFLECTOR SAVINGS AND BUCKLINGS FOR TYPE 5 CORE 


\subsection{STARTUP MARGIN}

Because. of the large fuel loading planned for the Type 5 core, it is necessary to incorporate a burnable poison, e.g., B-10 in the form of $\mathrm{ZrB} 2$, dispersed in the fuel matrix in order to meet all shutdown requirements with the 7 . control rods operat- . ing as a bank. The shutdown requirements are excess reactivity control throughout core life and shutdown for most reactive rod (central) stuck full out at most reactive condition. $\left(68^{\circ} \mathrm{F}\right.$, no xenon, midlife) .. Adjustments in the B-10 loading were made to yield a $3 \% \Delta \mathrm{K} / \mathrm{K}$ startup margin at the operating temperature $\left(440^{\circ} \mathrm{F}\right)$, with equilibrium xenon.

\section{2 .1 Worth of Substitution Effect}

Core:reactivities were calculated for configurations consisting of all fixed fuel elements employing the equivalent bare model, as described in Section. 3.1 . The negative reactivity effect of the substitution of 7 control rod fuel elements for 7. fixed fuel elements was estimated to provide the reactivity of the mixed core (38 fixed plus 7 control rod fuel elements). Previous analyses indicated the negative reactivity worths of the substitution effect for the SM-1 Core I(3) and $S M-2$ Core $I(5)$ to be 2.2 and $1.0 \%, \rho$, respectively, employing a two-group, two dimensional diffusion theory code, $\mathrm{PDQ}$.(12) These two type cores are similar to the Type 5 cores except for having smaller fuel loadings and lower metal-to-water volume ratios: Therefore, it is concluded that the negative substitution: worth for the Type 5 cores should be somewhat less than $1.0 \% \rho$, due to a higher metal-to-water ratio which yields a faster neutron spectrum, or smaller U-235 reactivity coefficient. However, to insure that the Type 5 cores possess sufficient startup margins, the negative substitution worth for the Type 5 . cores were taken to be $1.5 \% \rho$. In addition, this substitution worth was held invariant during the entire core life.

\subsubsection{Model Correction}

On the basis of reactivity investigations of various core configurations, (11) it has been fairly well established that use of modified two-group theory with $\mathrm{P}-1$ fast constants and P-3 thermal constants with hardened Maxwell-Boltzmann micro-

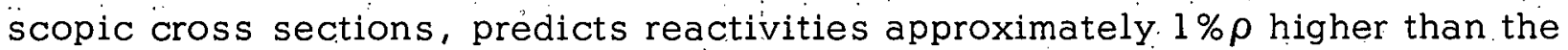
measured core: reactivities, for the hot condition. In addition, the comparison between analytical and measured core reactivities for the cold condition appears to be fairly good. Therefore, utilizing the results of these previous investigations, the following relations will be employed: analytical core reactivities are considered to overestimate measurements by $1 \% \rho$ for the høt $\left(440^{\circ} \mathrm{F}\right)$ condition, whereas exact agreement is assumed for the cold $\left(68^{\circ} \mathrm{F}\right)$ condition.

\section{2 .3 . Worth of Equilibrium Xenon}

The presence of equilibrium xenon for the hot $\left(440^{\circ} \mathrm{F}\right)$ condition was taken into account in the thermal group by defining $\mathrm{K}^{\prime}$ th ${ }^{\prime}$, 


$$
\mathrm{K}_{\mathrm{th}}^{\prime}=\frac{\nu \Sigma_{\mathrm{f}_{\mathrm{th}}}}{\sum_{\mathrm{a}_{\mathrm{th}}}+\sum_{\mathrm{a}}^{\mathrm{Xe}}}
$$

where $\sum_{a t h}$ is the thermal macroscopic cross section of the core excluding xenon, and $\Sigma_{a}^{x e}$ is the thermal cross section due to equilibrium xenon. The variation of $\Sigma_{a}^{x e}$ with burnup, is given by the relation, (7)

$$
\Sigma_{\mathrm{a}}^{\mathrm{Xe}}=\frac{\alpha \mathrm{X}\left(\gamma_{\mathrm{I}}+\gamma_{\mathrm{Xe}}\right) \sigma_{\mathrm{a}}^{\mathrm{Xe}}\left[\frac{\delta \mathrm{P}}{\mathrm{V}}\right]}{\lambda_{\mathrm{Xe}}+\sigma_{\mathrm{a}}^{\mathrm{Xe}} \beta\left[\frac{\delta \mathrm{P}}{\mathrm{V}}\right]\left[\frac{1}{(1-\bar{B}) \Sigma_{10}}\right]}
$$

The parameter, $\mathrm{X}$, is defined by the relation,

$$
\mathrm{X}=(1-\beta)+\beta \mathrm{g}^{\prime} \overline{(\mathrm{B})}
$$

where $g^{\prime}(\bar{B})$ is the average flux in the fuel plate divided by the average flux.in the entire fuel element, at an average fuel burnup, $B$, as obtained from the output of the P-3 code. (10) The parameter, $\beta$, defining the fraction of thermal fissions, is given by the relation,

$$
\beta=\frac{1}{K_{\text {eff }}} \cdot \frac{P \cdot K_{t h}}{\left(1+\tau B^{2}\right)\left(1+L^{2} B^{2}\right)},
$$

where $\mathrm{K}_{\text {eff }}$ is defined by Eq。(1)。

The parameters which are used in Eq。(4) independent of burnup, $\bar{B}$, are presented in Table 2 .

\subsection{DETERMINATION OF INITIAL B-10 LOADINGS}

For all of the possible Type 5 core configurations considered, the initial B-10 loading was adjusted to yield a $3 \% \rho$ startup margin for the mixed core : (38 fixed plus 7 control rod fuel elements), at $440^{\circ} \mathrm{F}$, with equilibrium xenon, and including a model correction factor. Core reactivities were determined employing the equivalent bare model based on modified two-group theory, as described in Section 3.1. The initial B-10. loading was calculated by use of the following relation:

$$
\rho_{\mathrm{I}}=\rho_{\mathrm{FE}}+\rho_{\mathrm{MC}}+\rho_{\mathrm{SE}}+\rho_{\mathrm{XE}} \text {; }
$$

where,

$$
\begin{aligned}
& \rho_{\mathrm{I}}=\text { actual initial reactivity }=3 \% \\
& \rho_{\mathrm{FE}}=\text { core reactivity for all fixed fuel elements } \\
& \rho_{\mathrm{MC}}=\text { model correction }=-1 \% \\
& \rho_{\mathrm{SE}}=\text { worth of substitution } \text { effect }=-1.5 \% \\
& \rho_{\mathrm{XE}}=\text { reactivity worth of equilibrium xenon }
\end{aligned}
$$


The B-I0. loading. was adjusted to fix the actual initial reactivity, $\rho_{I}$, at $3 \%$ 。

TABLE 2

XENON PARAMETERS FOR TYPE 5 CORE, $440^{\circ} \mathrm{F}$

\begin{tabular}{|c|c|c|c|}
\hline Parameter & Units & Description & Values \\
\hline$\alpha$ & - & Non-uniform xenon distribution factor & 1.134 \\
\hline$\gamma_{I}$ & - & Fractional fission yield of iodine & 0.060 \\
\hline$\gamma_{\mathrm{Xe}}$ & - & Fractional fission yield of xenon & 0.0029 \\
\hline$\sigma_{\mathrm{a}}^{\mathrm{Xe}}$ & $\mathrm{cm}^{2}$ & Xenon thermal absorption cross section & $2.9\left(10^{-18}\right)$ \\
\hline$\delta$ & $\begin{array}{l}\text { fissions/ } \\
\text { watt-ses }\end{array}$ & Fissions per watt per second & $3.2175\left(10^{10}\right)$ \\
\hline $\mathrm{P}$ & watts & Thermal power & $\begin{array}{ll}10^{7} & , S M-1 \\
2\left(10^{7}\right), & S M-1 A\end{array}$ \\
\hline V & $\mathrm{cm}^{3}$ & Active core volume & $1.3999\left(10^{5}\right)$ \\
\hline$\lambda_{\mathrm{Xe}}$ & $\sec ^{-1}$ & Decay constant of xenon & $2.092\left(10^{-5}\right)$ \\
\hline
\end{tabular}

\subsection{CORE ENERGY RELEASE}

The energy release of the Type 5 core was obtained by burning up the core uniformly, and applying a reactivity correction factor obtained from the difference between the uniform and non-uniform burnup behaviors of the SM-2 Core I。 (1)

\section{4 .1 Uniform Burnup}

The uniform burnup behavior of the Type 5 core was obtained by calculating the core reactivity as a function of average fuel burnup, employing the equivalent bare model (see Section 3.1). Fast and thermal nuclear core constants were calculated by use of the MUFT-III ${ }^{(8)}$ and two-dimensional P-3(10) machine codes, respectively. A preparation routine, Program $50(13)$, coded for the IBM 650 machine, was utilized to calculate the U-235 and B-10. loadings as functions of average fuel burnup, in addition to preparing the inputs to the MUFT-III and P-3 codes:

The relationship relating boron to uranium burnout, as used in Program 50 ; is given as: 


$$
\frac{N_{B}-I 0(t)}{N_{B-I 0}(0)}=\frac{N_{U-235}(t)}{N_{U}-235(0)} \Delta,
$$

where,

$$
\Delta=\frac{\left[\begin{array}{c}
\sigma \frac{B-1 Q_{t h}}{a_{t h}} \\
\sigma a_{t h}^{U-235}
\end{array}\right]\left(1+\alpha_{t h}\right) \beta+\left[\frac{\sigma a_{f}^{B-10}}{\sigma U-235}\right]\left(1+\alpha_{f}\right)(1-\beta)}{\left(1+\alpha_{t h}\right) \beta+\left(1+\alpha_{\mathrm{f}}\right) \cdot(1-\beta)}
$$

The Program 50 code is most accurately used when one re-calsulates the fraction uf thermal fission, $\beta$, to be used as an input parameter previous to each burnup time-step。 For purposes of expedition and efficiency, the value of $\beta$ was held constant throughout core life.

The effect of $\beta$ is such that an increasing $\beta$ with life implies that the burnable poison, $B-10$, burns up faster, thus yielding a higher maximum midlife reactivity at $68^{\circ} \mathrm{F}$ (see Section 3.5 ) and greater energy release over core life since: less B-10 residue remains at the end of life. Since $\beta$ actually increases monotonically with core life due to fuel and poison depletion, in order to obtain the most conservative core energy release, the minimum value of $\beta$ (occurring at the start of life) was used and held constant throughout core life. This selection of $\beta$ necessarily implied an underestimation of the maximum midlife reactivity at $68^{\circ} \mathrm{F}$.

A particular Type 5 core (plate thickness - 75 mils, clad thickness - 5 mils, and $\mathrm{w} / \mathrm{OUO}_{2}-40 \%$ ) was examined to find the effect of constant $\beta$ vs. variable $\beta$ on energy release and maximum reactivity。: The core was burned up uniformly using two different values of $\beta: 1,0$ and 0.14 (actual value at start of life). The uniform results, in addition to the corresponding non-uniform results, are presented in Fig。 8。

The actual value of $\beta$. for the uniform burnup, varies from 0.14 to 0.45 with increasing burnup, while it varles from 0.14 to 0.39 for the non-uniform burnup 。 Since $\beta=0.23$ at midlife (burnup fraction of 0.2 ), it is concluded that use of the minimum value of $\beta=0.14$ in Program 50 probably underestimates the actual value of the maximum reactivity by at most $1 \% \rho$, for the Type 5 cores; as can be seen from Fig. 8, the difference in $\rho$ between $\beta=0.14$ and 1 is only $2 \%$. In addition。 the effect of a constant (minimum) value of $\beta$ on core energy release is relatively small。

\section{4 .2 Non-Uniform Burnup}

The -energy release of the Type 5 core was obtained by means of "synthesized" non-uniform burnup calculations. Reactivity vs average fuel burnup fraction was calculated by applying a non-uniform reactivity correction factor to uniform burnup "calculations of the Type 5 core based on the difference between the uniform and 


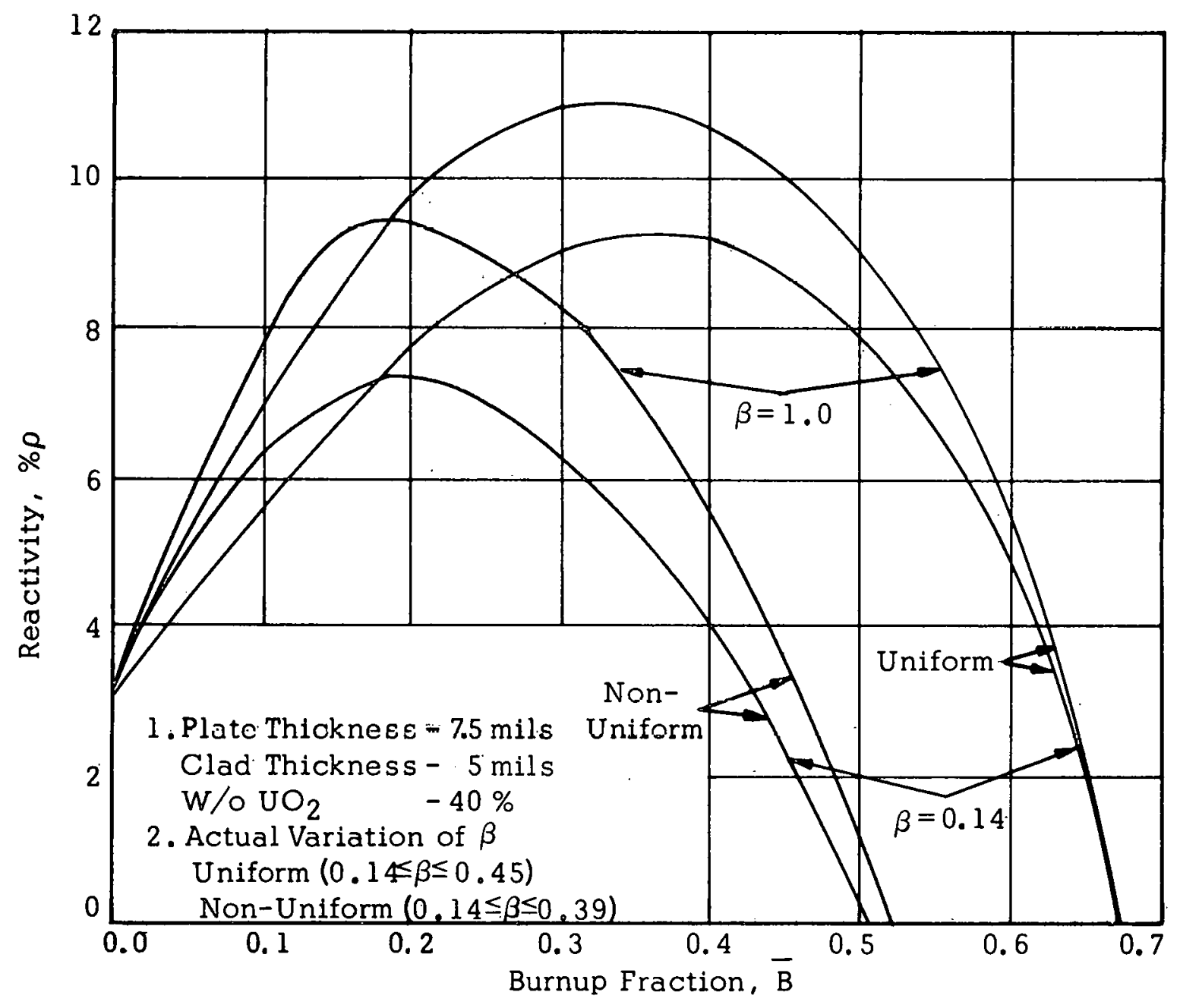

Figure 8. Type 5 Core Reactivity Vs Burnup 
non-uniform burnups of the SM-2 Core I. (1) The non-uniform burnup behavior of the SM-2 Core I was based upon non-uniform fuel and poison depletion calculations in the axial and radial directions. Figure 9 presents the difference in reactivity (non-uniform minus uniform) as a function of average fuel burnup fraction for the SM-2 Core I that was used as a reactivity correction factor to the uniform burnup of the Type 5 cores.

The energy release in MWYR was obtained from the average fuel burnup fraction by considering that depletion of $1 \mathrm{~kg}$ of $\mathrm{U}-235$ yielded. 2 MWYR in core life.

It has been found that for the SM-1 Core $1,(1)$ employment of the relation, I.5 MWIR/kg U-235 depleted, with the uniform burnup behavior, predicts the measured core energy release reasonably: well. A particular Type 5 core (75-mil plate, 10-mil clad, and $40 \mathrm{w} / \mathrm{O} \mathrm{UO}_{2}$ ) was examined. Using the Type 3 nonuniform burnup correction factor with the Type 5 uniform burnup and 2 MWYR/kg U-235, an energy release prediction of 104.2 MWYR was obtained. Employing the Type 5 uniform burnup with $1.5 \mathrm{MWYR} / \mathrm{kg} \mathrm{U}-235$, the energy release was calculated to be:105.9 MWYR, indicating very close agreement。

\section{4 .3 Use of Calculational Design Technique}

In order to obtain a sufficiently complete dependence of core energy release on plate thickness $(50-100 \mathrm{mils})$, clad thickness $(5-10 \mathrm{mils})$, and w/o $\mathrm{UO}_{2}(35-45 \%)$, a three-level factorial design, would be required; i。e., 3 points per variable, or $(3)^{3}-27$ - cases be analyzed in detail. Instead, use was made of a calculational design technique (14); $i_{0} e_{0}$, substitution of a calculational design with a reduced number (15) of calculations with certain specified combinations of variables for the standard three-level design. From these cases a quadratic empirical equation, with interaction terms, relating the core energy release to the variable inventory can be obtained by use of least squares fits. The empirical equation is amenable to graphical display and optimization by use of partial differentiation. An error analysis yielded a coefficient of variation of $1.2 \%$, indicating a sufficiently accurate fit of the empirical equation to the 15 detailed calculations for energy.release.

In addition to the predicted results for core energy.release, a condensed receipe:for obtaining the empirical equation is presented in this section. For practically all of the work in reactor physics analysis (14)(15) an assumed quadratic empirical equation, with interaction terms, has been substantiated by analysis of variance. The general form of the desired empirical equation is:

$$
\begin{aligned}
y & =B_{0}+B_{1} x_{1}+B_{2} x_{2}+\ldots+B_{n} x_{n} \\
& +B_{11} x_{1}^{2}+B_{22} x_{2}^{2}+\ldots+B_{n n} x_{n}^{2} \\
& +B_{12} x_{1} x_{2}+B_{13} x_{1} x_{3}+\ldots+B_{1 n} x_{1} x_{n} \\
& +B_{23} x_{2} x_{3}+\ldots+B_{2 n} x_{2} x_{n}+\ldots+B_{n-1: n} x_{n-1} x_{n}
\end{aligned}
$$




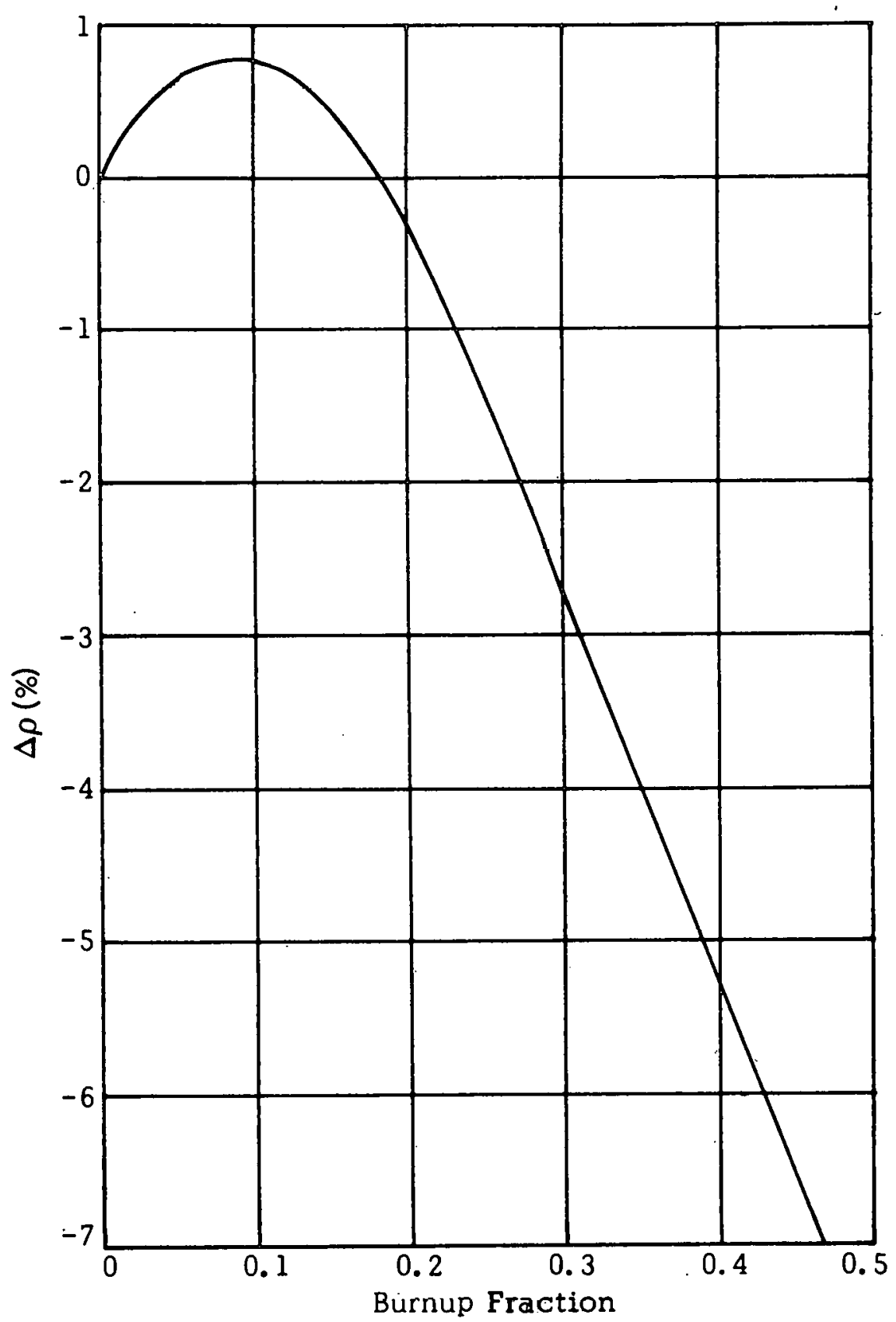

Figure 9. SM-2 Core I, Type 3 - Reactivity Change (Non-Uniform Minus Uniform Burnup)

Vs Burnup 
where,

Y

$\mathrm{x}_{1}, \mathrm{x}_{2}, \ldots, \mathrm{x}_{\mathrm{n}}$

$\mathrm{B}_{\mathrm{O}}$

$B_{1}, B_{2}, \ldots, B_{n}$

$\mathrm{B}_{11}, \mathrm{~B}_{22}, \ldots, \mathrm{B}_{\mathrm{nn}}$ is the dependent variable, i.e., energy release, of interest from the empirical equation.

are the $\mathrm{n}$ independent variables in coded form.

is the value of $y$ at the origin of the $n$-dimensional space.

are the coneffirients of the linear terms,

are the coefficients of the quadratic terms.

$\mathrm{B}_{12}, \mathrm{~B}_{13}, \ldots, \mathrm{B}_{\mathrm{n}-1, \mathrm{n}}$ are the coefficients of the interaction terms.

It is convenient to assign coded values to the independent variables to permit separate and independent evaluation of each of the coefficients of the empirical equation. In doing so, one must deal with the following equation which is basic in regression analysis:

$$
\begin{aligned}
y & =A_{0}+A_{1} x_{1}+A_{2} x_{2}+\ldots+A_{n} x_{n} \\
& +A_{11}\left(x_{1}^{2}-K\right)+A_{22}\left(x_{2}^{2}-K\right)+\ldots+A_{n n}\left(x_{n}^{2}-K\right) \\
& +A_{12} x_{1} x_{2}+A_{13} x_{1} x_{3}+\ldots A_{n-1, n} x_{n-1} x_{n}
\end{aligned}
$$

where,

$$
\therefore \mathrm{K}=\frac{\sum_{\ell=1}^{\mathrm{m}} \mathrm{x}_{1 \ell}^{2}}{\mathrm{~m}}=\frac{\sum_{\ell=1}^{\mathrm{m}} \mathrm{x}_{2 \ell}^{2}}{\mathrm{~m}}=\ldots=\frac{\sum_{\ell=1}^{\mathrm{m}} \mathrm{x}_{\mathrm{n} \ell}^{2}}{\mathrm{~m}}
$$

and,

$$
\begin{aligned}
& B_{0}=A_{0}-K\left(A_{11}+A_{22}+\ldots+A_{n n}\right) \\
& B_{1}=A_{1}, \ldots, B_{n}=A_{n} \\
& B_{11}=A_{11} \ldots, B_{n n}=A_{n n} \\
& B_{12}=A_{12}, \ldots, B_{n-1, n}=A_{n-1, n}
\end{aligned}
$$

For the above equations. $m$ is the number of calculational points required and is given by

$$
m=2^{n}+2 n+1
$$


where $\mathrm{n}$ is the number of independent variables. The subscript $\ell$ indicates $\ell^{\text {th }}$ calculational point; $e . g \circ x_{36}$, is the value of $x_{3}$ for the 6 , calculational point.

The equation: in A's is solved by the method of least squares employing partial differentiation. Linear transformations of the independent variables; $\mathrm{x}_{\mathrm{i}}$, to coded values has been found suitable as confirmed by an analysis of variance.. To permit separate and independent evaluation of the " $A$ " coefficients, the maximum and minimum actual values of the independent variables must correspond to + $\delta$ and $-\delta$, respectively, where $\delta=1.2154$ for a 3-variable case. The existence of the quantity $\delta \neq 1]$ is established to give orthogonality permitting the coefficients to be evaluated.

The formulas for the A coefficients are as follows:

$$
\begin{aligned}
& A_{0} \quad=\frac{\sum_{\ell=1}^{m} y_{l}^{\prime}}{m} \\
& A_{n} \quad=\frac{\sum_{l=1}^{m} y_{l}^{\prime} x_{n}}{\sum_{\ell=1}^{m}\left(x_{n}\right)^{2}} \\
& A_{n n}:=\frac{\sum_{\ell=1}^{m} y_{\ell}^{\prime}\left(x_{n_{\ell}}^{2}-K\right)}{\sum_{\ell=1}^{m}\left(x_{n_{\ell}}^{2}-K_{l}\right)^{2}} \\
& \therefore A_{n-1, n}=\frac{\sum_{\ell=1}^{m} y_{\ell}^{\prime}\left(x_{n-1}\right)\left(x_{n}\right)}{\sum_{\ell=1}^{m}\left(x_{n-1}\right)_{l}^{2}\left(x_{n}\right)_{l}^{2}}
\end{aligned}
$$
In the above equations, the quantity, ' $y^{\prime} l$ ' is the actual value of $y$ obtained in
'the $l^{\text {th }}$ calculation.

Figure 10 presents calculational design showing the 15 detailed calculations to be performed to formulate the quadratic equation. This selection is based upon statistical methods, and has been shown to be quite sufficient.(14)

Figures 11,12, and 13 present the variation of core energy release for the Type 5 core ( 38 fixed plus 7 control rod. fuel elements) with plate thickness, parametric in clad thicknessard'w/o $\mathrm{UO}_{2}$ in the meat. It is observed that the Type 5 core is undermoderated for plate thicknesses greater than $90 \mathrm{mils}$ and overmoderated for $80 \mathrm{mils}$ and less, from the standpoint of energy release optimization. 


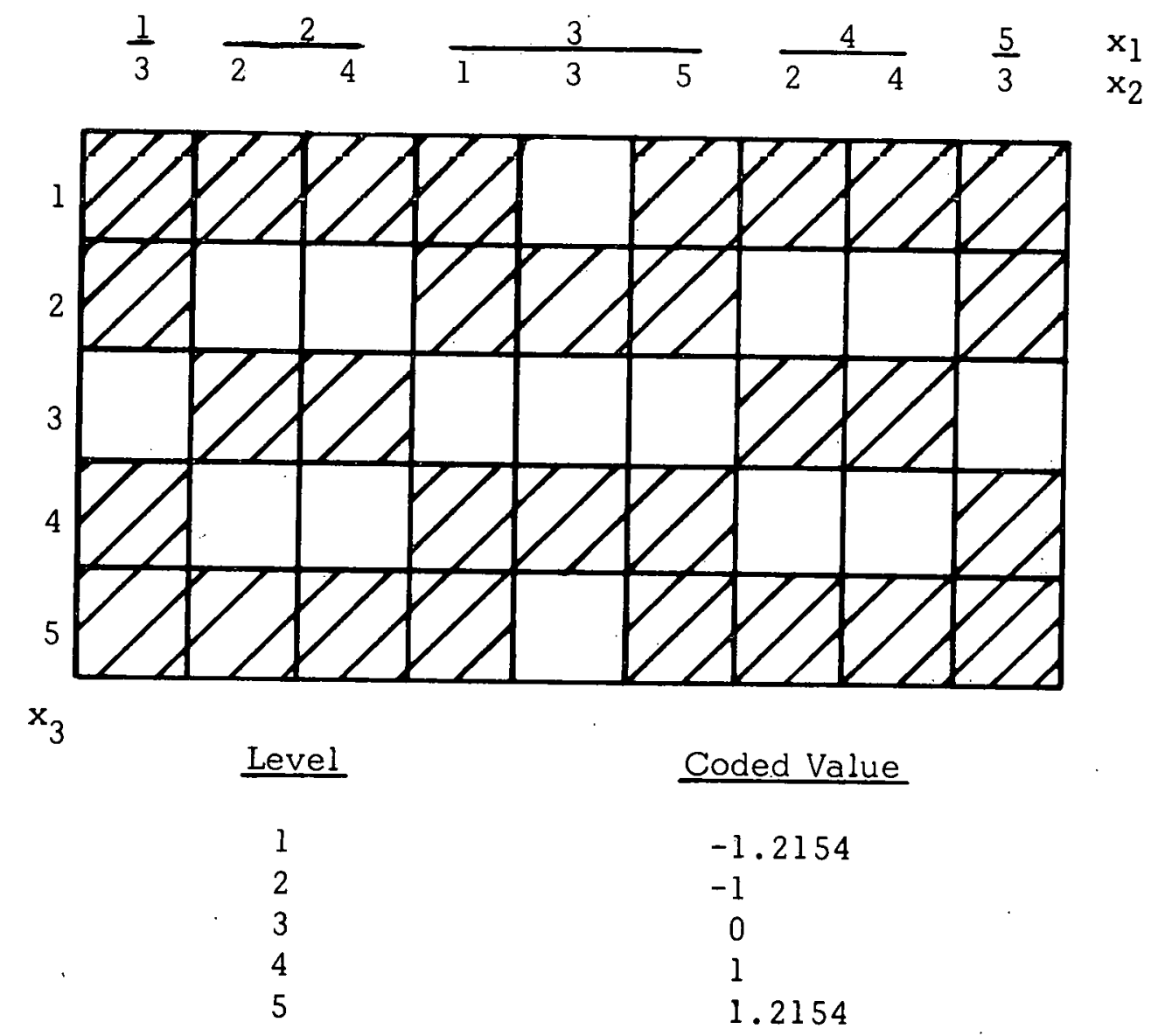

NOTE: Blank spaces correspond to 15 calculational cases.

Figure 10. Three-Factor Box Design 


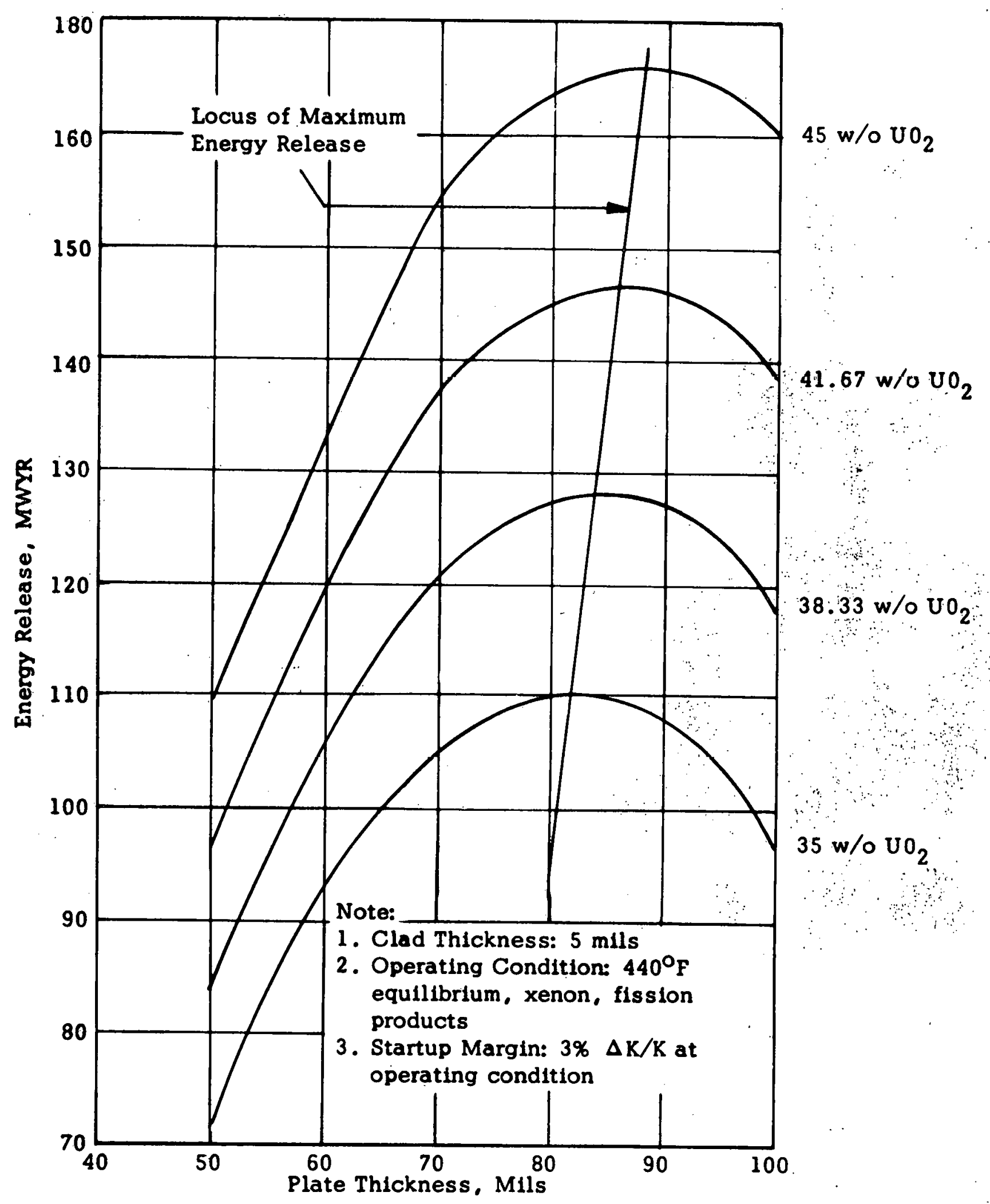

Figure 11. Energy Release Vs. Plate Thickness for Type 5 Core (45 fuel elements) 


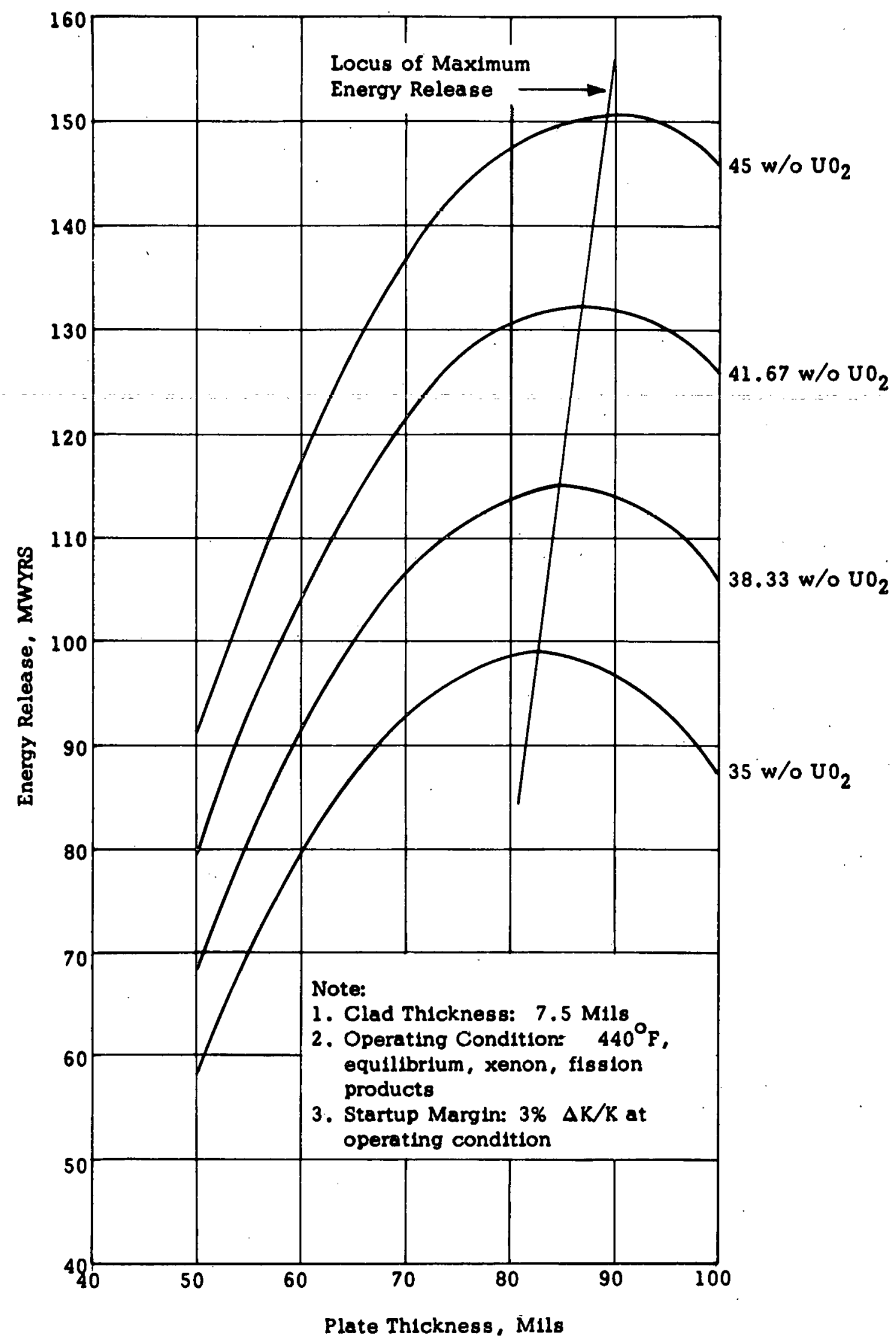

Figure 12. Energy Release Vs. Plate Thickness for Type 5 Core (45 fuel elements) 


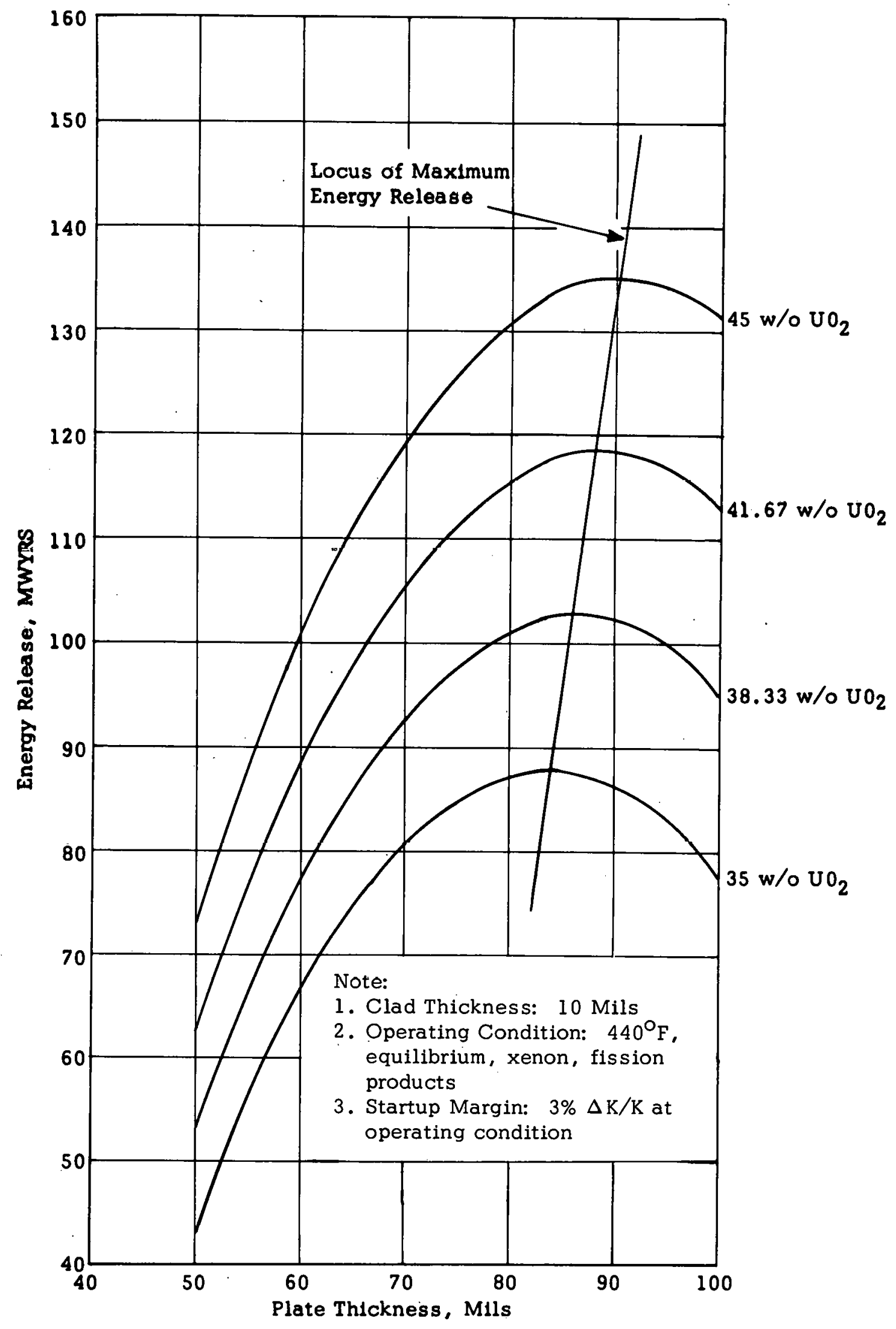

Figure 13. Energy Release Vs. Plate Thickness for Type 5 Core (45 fuel elements) 


\section{$3.5:$ MAXIMUM EXCESS REACTIVTY}

The maximum mid-life reactivity, at $68^{\circ} \mathrm{F}$, was computed by assuming the temperature defect remained invariant throughout core life. The temperature defect was directly: calculated at the start-of-life employing the equivalent bare model with fast and thermal nuclear core constants obtained from the MUFT-III, and two-dimensional P-3 machine codes, respectively. For the 15 Type 5 cores investigated, the temperature defect was found to slightly decrease from 5.0 to $2: 5 \% \rho$ with increasing plate thickness。

Figure: 14 presents the dependence of maximum reactivity $\left(68^{\circ} \mathrm{F}\right)$ on plate thickness as obtained from the 15 detailed calculations. It is observed that the maximum reactivity varies nearly: linearly; with the plate thickness being essentially independent of the clad thickness and $\mathrm{w} / \mathrm{O} \mathrm{UO}_{2}$. The maximum reactivity is primarily governed by the ratio of $B-10$ atoms to $U-235$ atoms at start-of-life. Since this ratio has been found to decrease with increasing plate thickness (or metal-to-water volume ratio) it is clear that the maximum reactivity should be a monotonically decreasing function of plate thickness The prediction of a linear behavior is not at all obvious.

It is also seen from Fig. 14 that practically all of the Type 5 core configurations should probably meet. the shutdown requirements as described in Section 3.2 , since the 7 control rod bank is worth approximately $23 \% \rho$ in reactivity, while the central rod (highest worth) is worth approximately $5 \% \rho$ 。

\section{$3.6 \quad$ AVERAGE FUEL BURNUP FRACTION . \\ The average fuel burnup fractions were found to vary between 0.32 and 0.58 for the ranges of the variable inventory considered.}

\subsection{WORTH OF BORON-10 A.T START-OF-LIFE}

The worth of B-10 at the start-of-life was calculated to vary between 0.02 and $0.12 \% \rho \% \mathrm{gm}$ for the ranges of the variable inventory considered. figurations 。

Table 3 presents the pertinent nuclear properties of the 15. Type 5 core con-

\subsection{PRELIMINARY POWER DISTRIBUTIONS AND PEAKING FACTORS}

A particular Type 5 core $\left(70-m i l\right.$ plate, 5 -mil clad, and $\left.38 \cdot \mathrm{w} / \mathrm{O} \cdot \mathrm{UO}_{2}\right)$ was selected to obtain preliminary power distributions and peaking factors in the axial and radial directions for thermal analysis presented in Section 4.0 。 


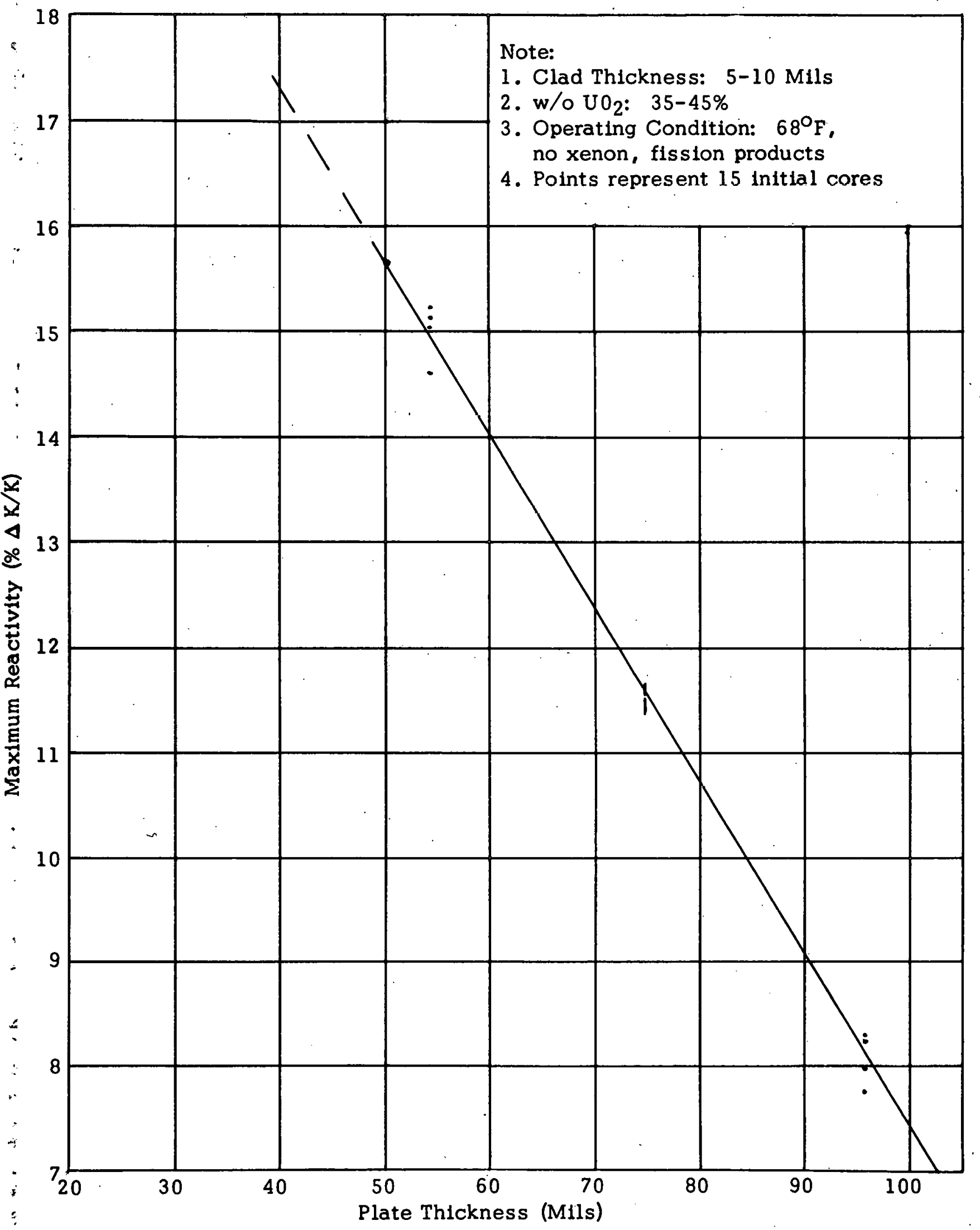

Figure 14. Maximum (Mid-life Reactivity Vs. Plate Thickness for Type 5 Core 
TABLE 3

NUCLEAR PROPERTIES OF $\frac{\text { TABLE }}{15 \text { TYPE }} 5$ CORE CONFIGURATIONS

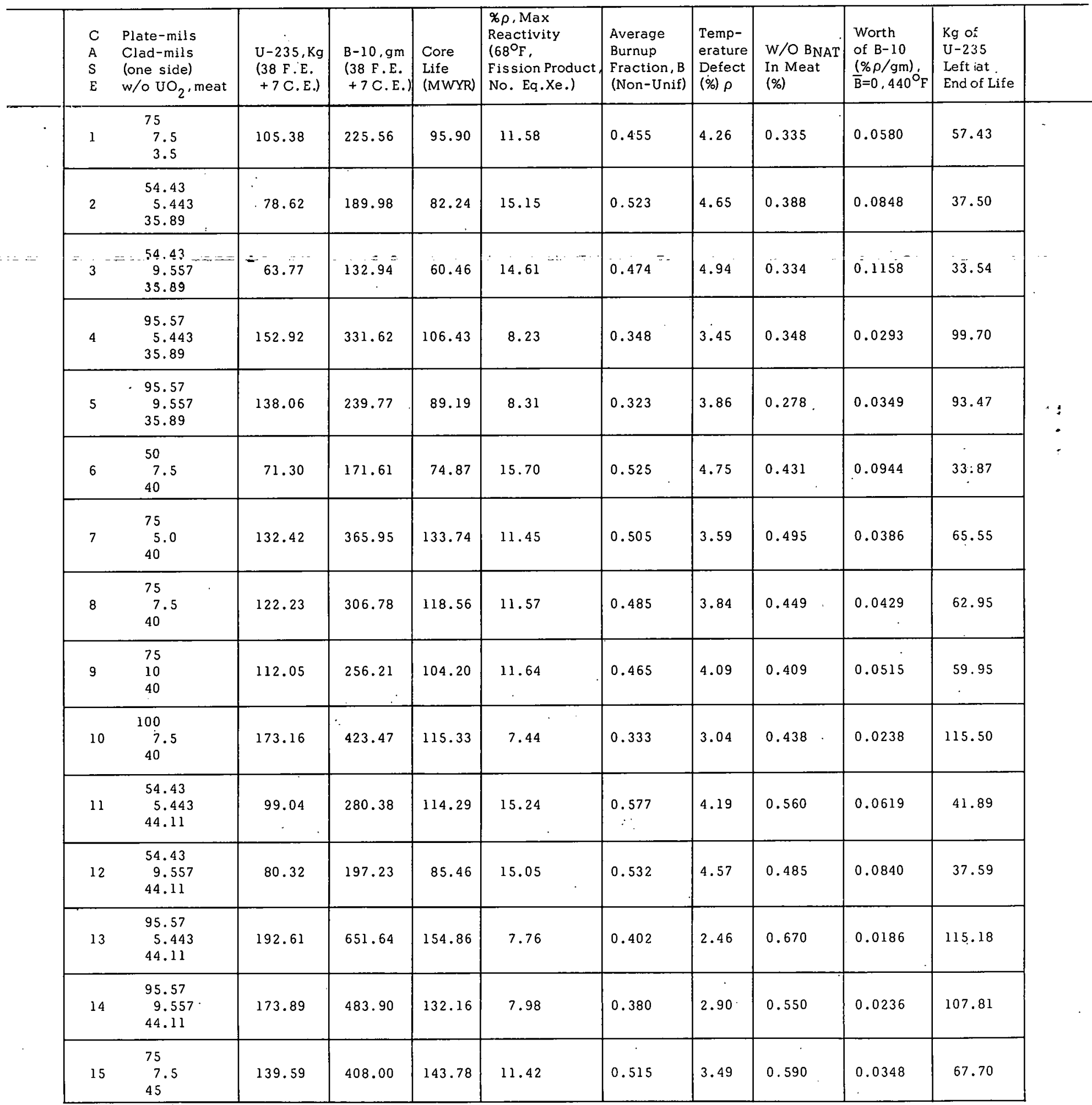




\subsubsection{Axial Power Distribution}

The most adverse axial power distribution, occurring approximately at midlife, was selected for analysis to provide conservative axial peaking factors. Europium flux suppressors, located at the bottom of the core, were included in the analysis.

\subsubsection{Calculation of $\Sigma_{\mathrm{p}}$ for Use in WINDOWSHADE Code}

The two-group, one-dimensional diffusion theory code, WINDOWSHADE, (16) for the IBM 650 machine, was employed to predict the axial power distribution. The WINDOWSHADE code recognizes two types of regions in the core: rodded and unrodded. The rodded region is treated by adding a thermal poison cross section. $\Sigma_{\mathrm{p}}$, to the thermal cross. section of the unrodded region, with the sum, $\Sigma_{\mathrm{a}_{\mathrm{t}}}+$ $\Sigma_{p}$, representing the effective thermal cross section of the rodded region. The following scheme was used to derive $\Sigma_{\mathrm{p}}$. The equivalent bare model, described in Section 3.1, was used as the basic equation. The following relations are defined:

$$
\begin{aligned}
\mathrm{K}_{\text {th }}^{\text {out }} & =\frac{\nu \sum_{\mathrm{f}_{\mathrm{th}}}}{\sum_{\mathrm{a}_{\mathrm{th}}}}, \text { rods out } \\
\mathrm{K}_{\text {th }}^{\text {in }} & =\frac{\nu \Sigma_{\mathrm{f}_{\mathrm{th}}}}{\sum_{\mathrm{a}_{\mathrm{th}}}+\Sigma_{\mathrm{p}}}, \text { rods in }
\end{aligned}
$$

The difference in $K_{\text {eff }}, 1 . e, K_{\text {eff }}^{\text {out }}-K_{\text {eff }}^{\text {in }}$ is set equal to the total 7 rod bank worth in terms of $\mathrm{K}_{\mathrm{eff}}$. Now the 7 rod bank worth has been measured to be approximately for the Type 5 core $23 \%$ in the SM-1 core. It is felt that the bank worth should be $\$ 34 \pm 3$ from the bottom ore. The 7, rod bank position, at midlife was calculated to be 7 ; in. rod: worth vs bank the active core. Using the measured integral rod worth, i.e., rod: worth vs bank position, the following relations were obtained corresponding to
a 7 in. bank position:

$$
\begin{aligned}
& \mathrm{K}_{\text {eff }}^{\text {out }}=1.15 \sim 13 \% \rho \\
& \mathrm{K}_{\text {eff }}^{\text {in }}=0.91 \sim-10 \% \rho
\end{aligned}
$$

Therefore,

$$
\mathrm{K}_{\text {eff }}^{\text {out }}-\mathrm{K}_{\text {eff }}^{\text {in }}=0.24
$$

or, finally.

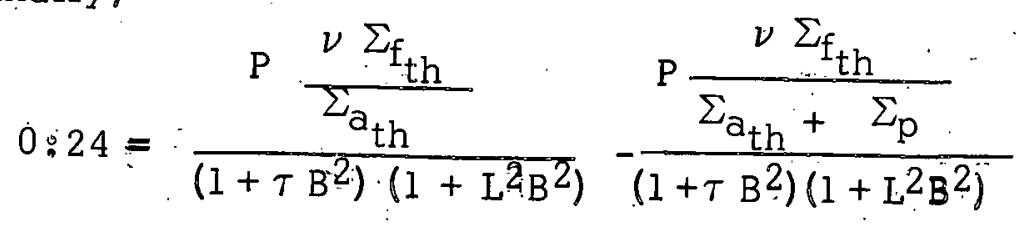


Solving, one obtains,

$$
\Sigma_{\mathrm{p}}=0.63
$$

U sing the value of $\Sigma_{p}$, the WINDOWSHADE code calculated $K_{\text {eff }}$ to be: $0.995^{\circ}$. for the midlife mockup. This condition is sufficiently close to criticality to use the predicted axial power distribution in further analysis. Figure 15 presents the analytical axial power distribution corresponding to the midlife condition of the pàrticular Type 5 core.

\section{8 .2 Radial Power Peaking Factors}

The most adverse radlal power peaking factors, occurring at the start-of-life, were obtained by applying correction factors to the local peaking factors of the SM-2 Core I. The correction factors were based on the difference between the gross radial power distributions of the homogeneous Type $3,1 . e_{0}, S M-2$ Core I, and Type 5 cores as predicted by the two-group one-dimensional diffusion theory code, VALPROD; (18) for the: IBM .650 machine. The maximum-to-average radial power peaks were found to be 1.9 and 2.6 for the Type 3 and Type 5 cores. respectively. Thus, for any peaking factor $\mathrm{P}$ :

$$
P \text {. (Type 5) } \equiv \frac{2.6}{1.9} \text { P. (Type 3) }
$$

Table 4 lists the power generation rate at the hottest spot, $Q(\Delta \theta)$, and the power generation rate at the hottest plate, $Q(\Delta \mathrm{T})$ for the Type 5 core (7.0-mil plate。 $5-\mathrm{mil} \mathrm{clad}$, and $38 \cdot \mathrm{w} / \mathrm{OUO}_{2}$ ) in the $\mathrm{SM}-1$ and $\mathrm{SM}-1 \mathrm{~A}$ core arrays, at the start of life.

TABLE 4

RADIAL POWER GENERATION FACTORS FOR'TYPE' 5 CORE'IN SM-1

AND SM-IA ARRAYS

(Hottest Elements: Start-of -Lifel

$\begin{array}{lccc}\text { Core } & \text { Element No } & Q(\Delta \theta) & Q(\Delta T) \\ S M-1 & 31 & 2.73 & 2.03 \\ S M-1 A & 16 & 2.72 & 1.67\end{array}$

This core has a greater fuel loading than the reference core (see Section 5.0 ), and thus should yield more adverse power generation rates.

The maximum-to-average axial power peak was calculated to be' 1.81 for the Type 5 core in the SM-1 array, and is assumed to be the same in the SM-1A array. Therefore, the most adverse preliminary maximum-to-average power generation in the SM-1 and SM-1A cores is 4.94 and 4.92 , respectively. This compares with 3.99 and 3.96 for Type 3 cores: 


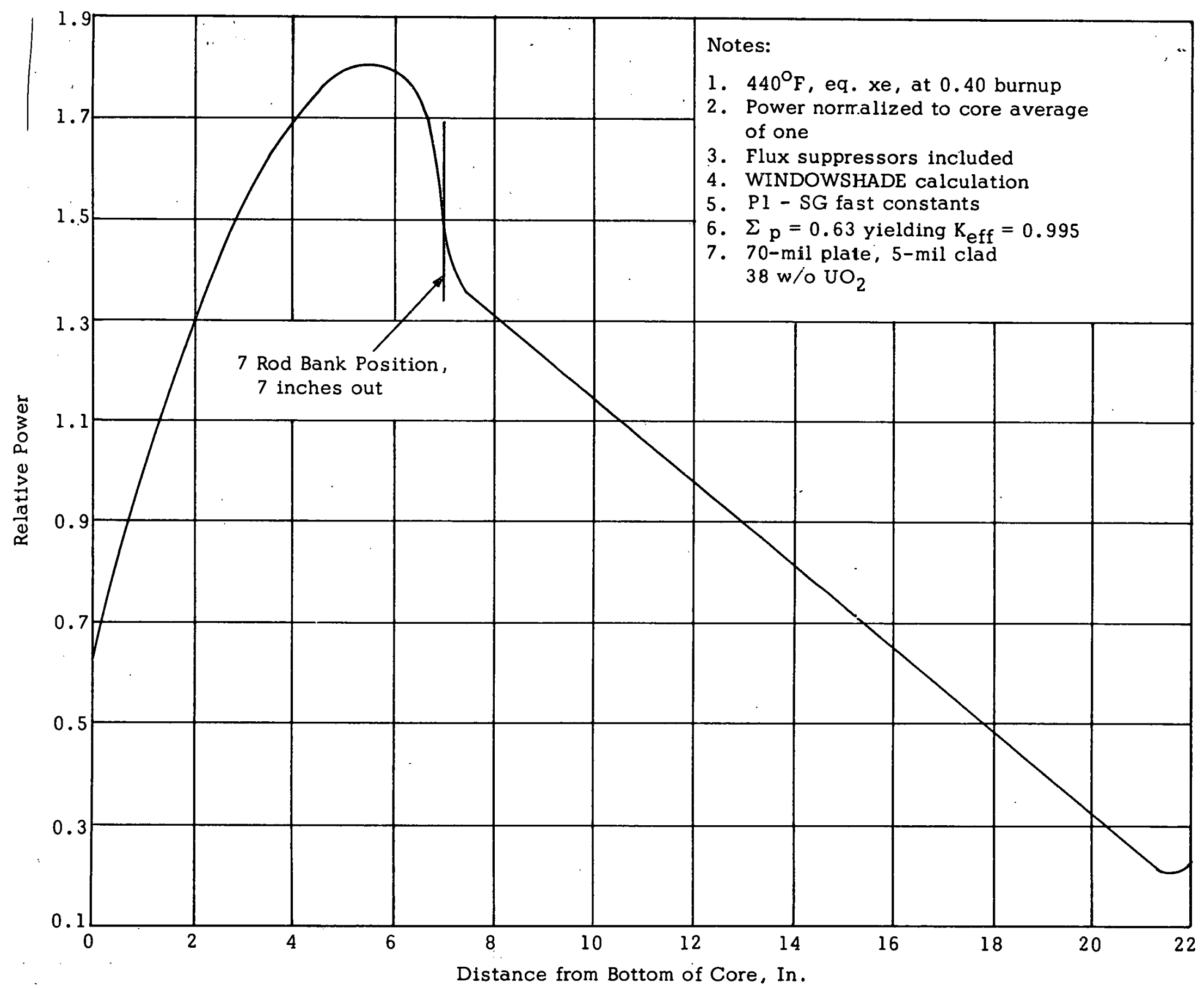

Figure 15. Relative Axial Power Distribution Type 5 Elements in SM-1 Array 


\subsection{THERMAL-HYDRAULIC ANALYSIS}

\section{. 4.I HOT CHANNEL ANALYSIS}

Thermal parameter surveys were performed on the SM-1 and SM-1A Type 5 cores, consisting of 50-100 mil plates containing $38 \mathrm{w} / 0 \mathrm{UO}_{2}$ and having cladding thicknesses of 5,8 and 10 mils. These surveys were conducted to determine the effects on channel thickness and power distribution upon the DNBR, nominal. and hot channel thermal perfformanoc and fuel plate thet mal stress.

To abbreviate the survey, the hottest element within each core was selected for analysis. Considering the highest elemental power to flow ratio to define the hot channel, element position 31 for the SM-1 core and element position 67 for the SM-1A core, were chosen.

A theoretical hot channel for each element analyzed was formulated using hot channel factors based on Type 3 deviations on spacing specifications. Flow maldistribution data was extrapolated from Type 3 fuel element flow testing. (19) The thermal survey for steady state conditions was performed using the IBM 704 Code STDY-3.(20)

Results from this survey indicate that the minimum DNBR is almost invariant with plate thickness as indicated on Fig. 16 and 17. Figures 18 and 19 show the variation in nominal channel pressure drop for various plate thicknesses.

Channel pressure drop data was obtained from the STDY-3 code to determine the effects of thicker plates on overall loop pressure drop. Figure 20 indicates for the SM-1A the increase in overall loop pressure drop fifor various plate configurations. Similar results were obtained for the SM-1 primary loop, however, smaller variations in pressure drop were noted.

Neither local nucleate nor bulk boiling occurred in the nominal or hot channels for any of the SM-1A plate configurations analyzed. However, in the SM-1 core local nucleate and bulk boiling did occur in the hot channels at scram power level, 13.45 Mw for all plate configurations analyzed. Local nucleate and bulk boiling was not found in the SM-1 nominal channels.

\subsection{THERMAL STRESS ANALYSIS FOR TYPE 5 FUEL PLATES}

\subsubsection{Stress Induced by Temperature Variation Across Thickness of Plate}

The generation of heat in Type 5 fuel plates: leads to a temperature variation in the plate. This temperature variation in turn induces thermal stresses o An analysis has been performed for calculating the thermal stresses induced in a plane in which the temperature varies through the thickness. The assumptions are as follows: 


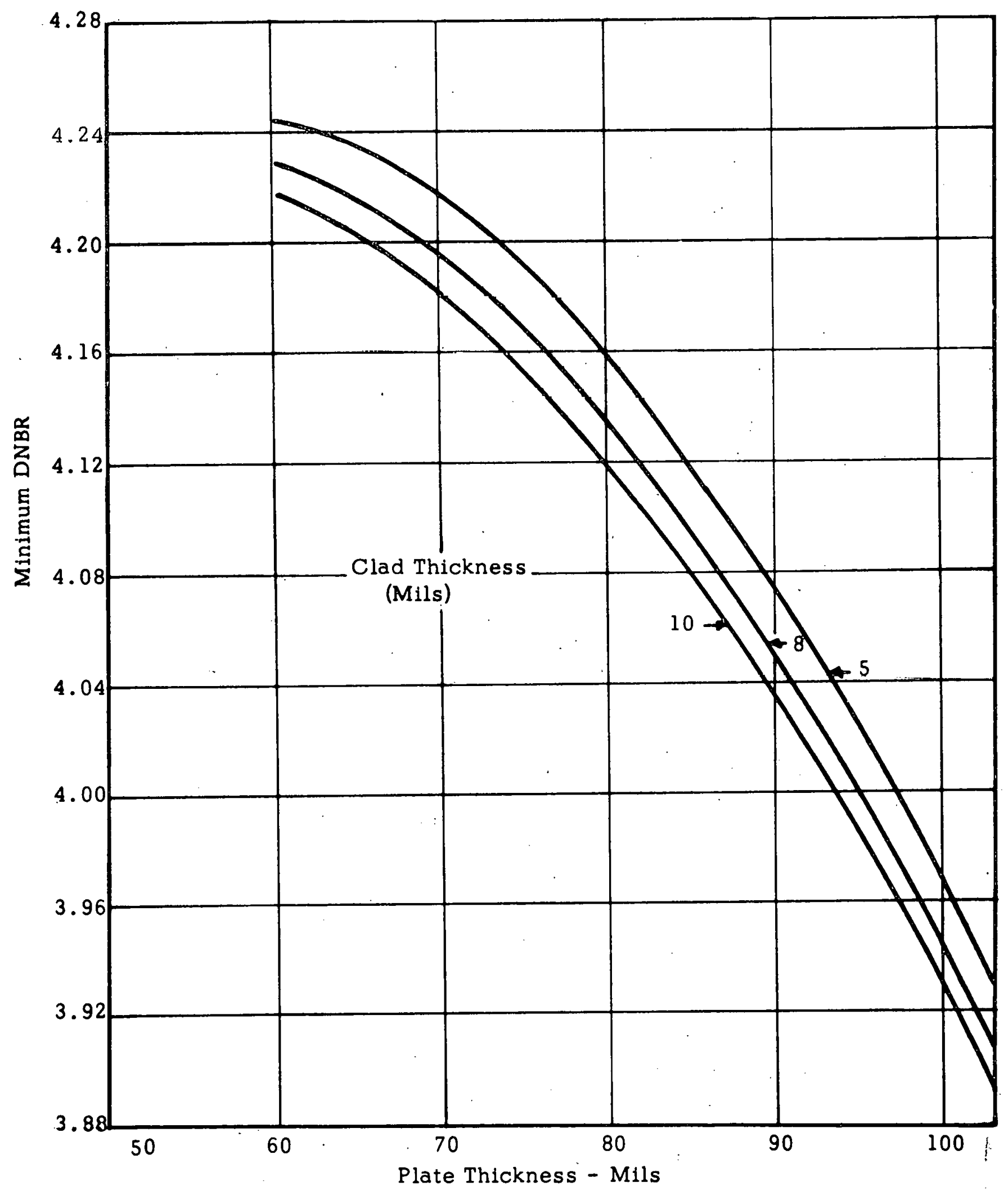

Figure 16. Minimum DNBR Vs. Plate Thickness - SM-1 Type 5 Core -10.77 MW 


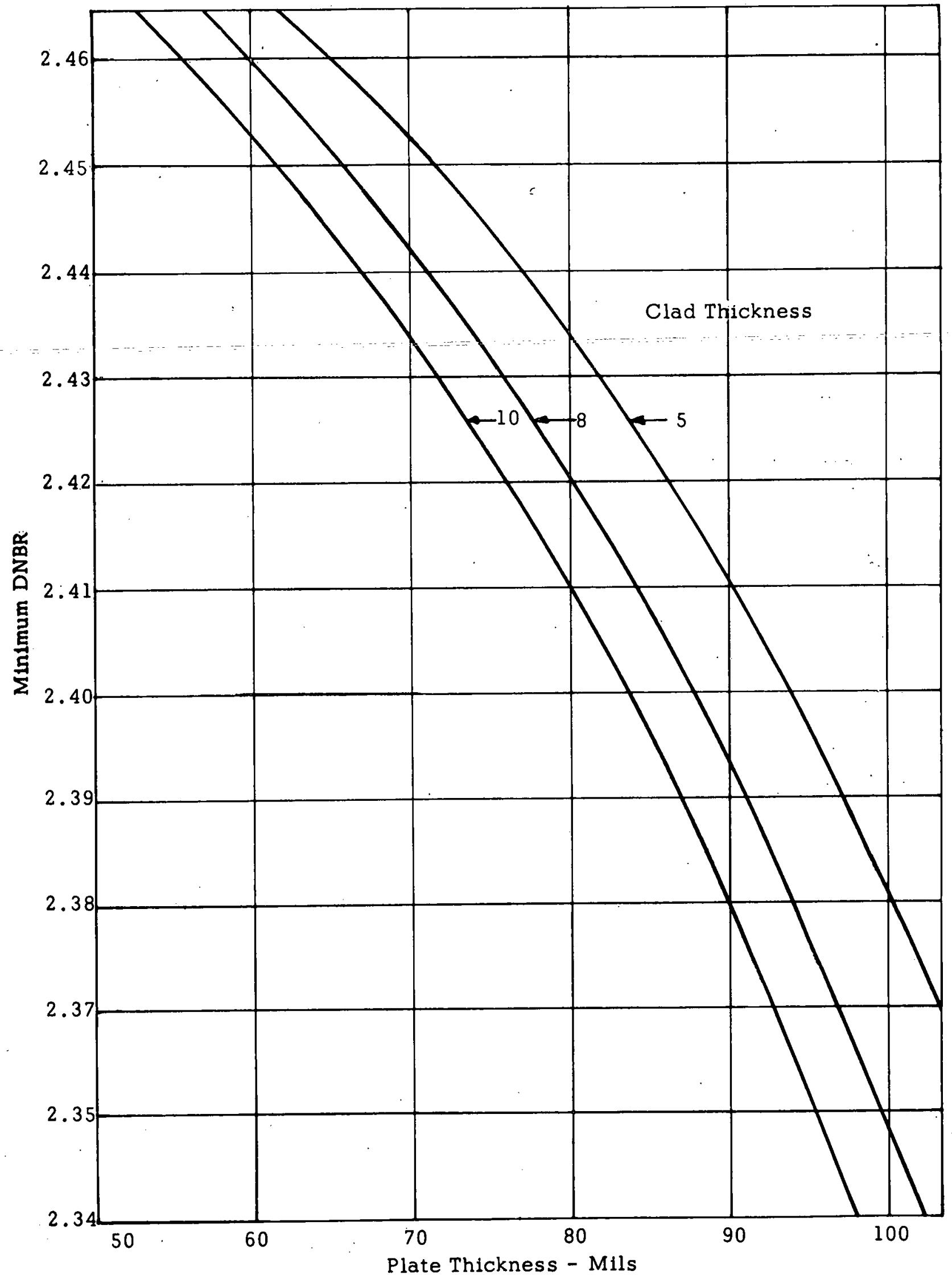

Figure 17. Minimum DNBR Vs. Plate Thickness - SM-1A Type 5 Core - 20 MW 


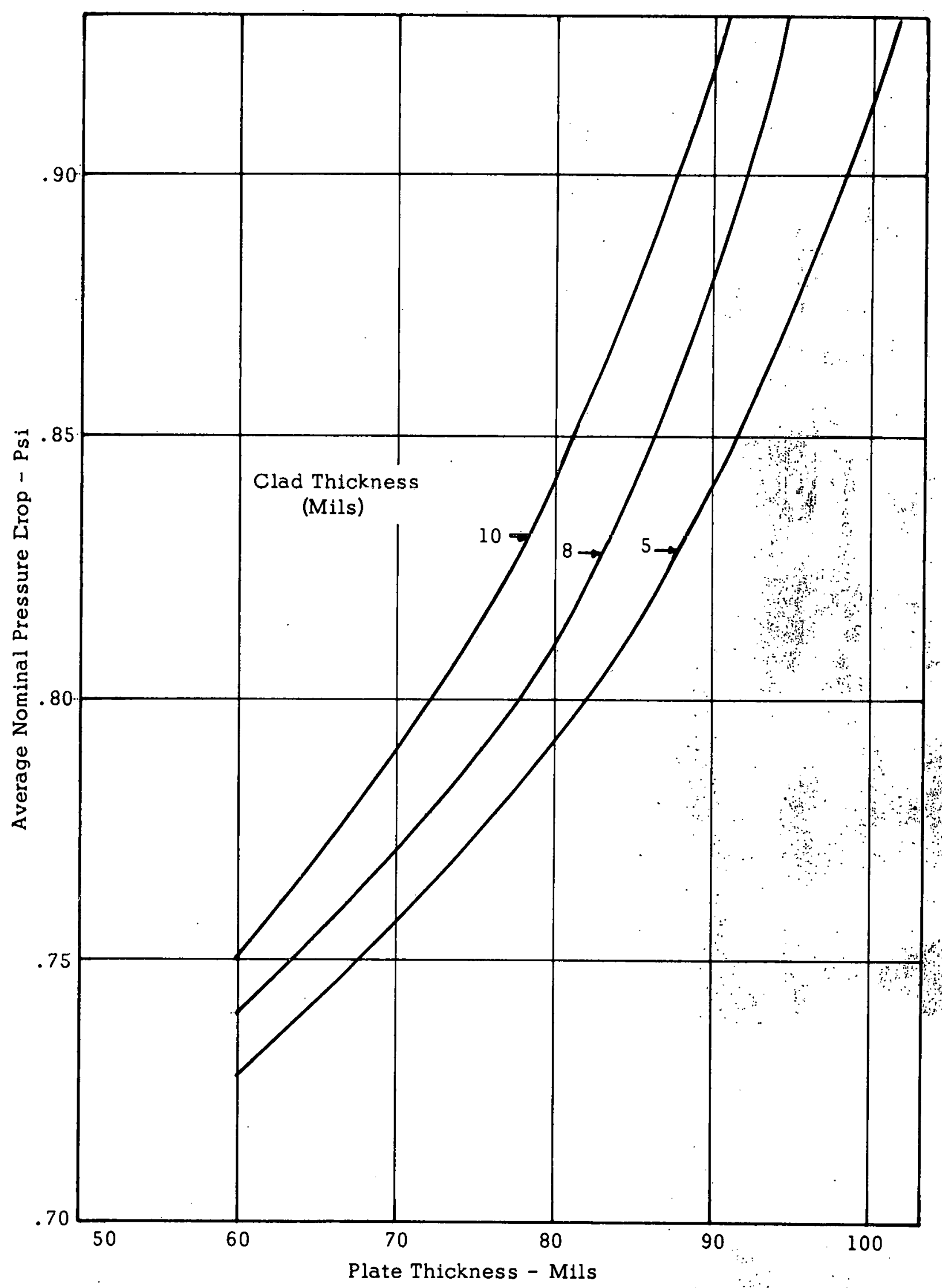

Figure 18. Average Pressure Drop Vs Plate Thickness, SM-1 Type 5 Core, 10.77 Mw 


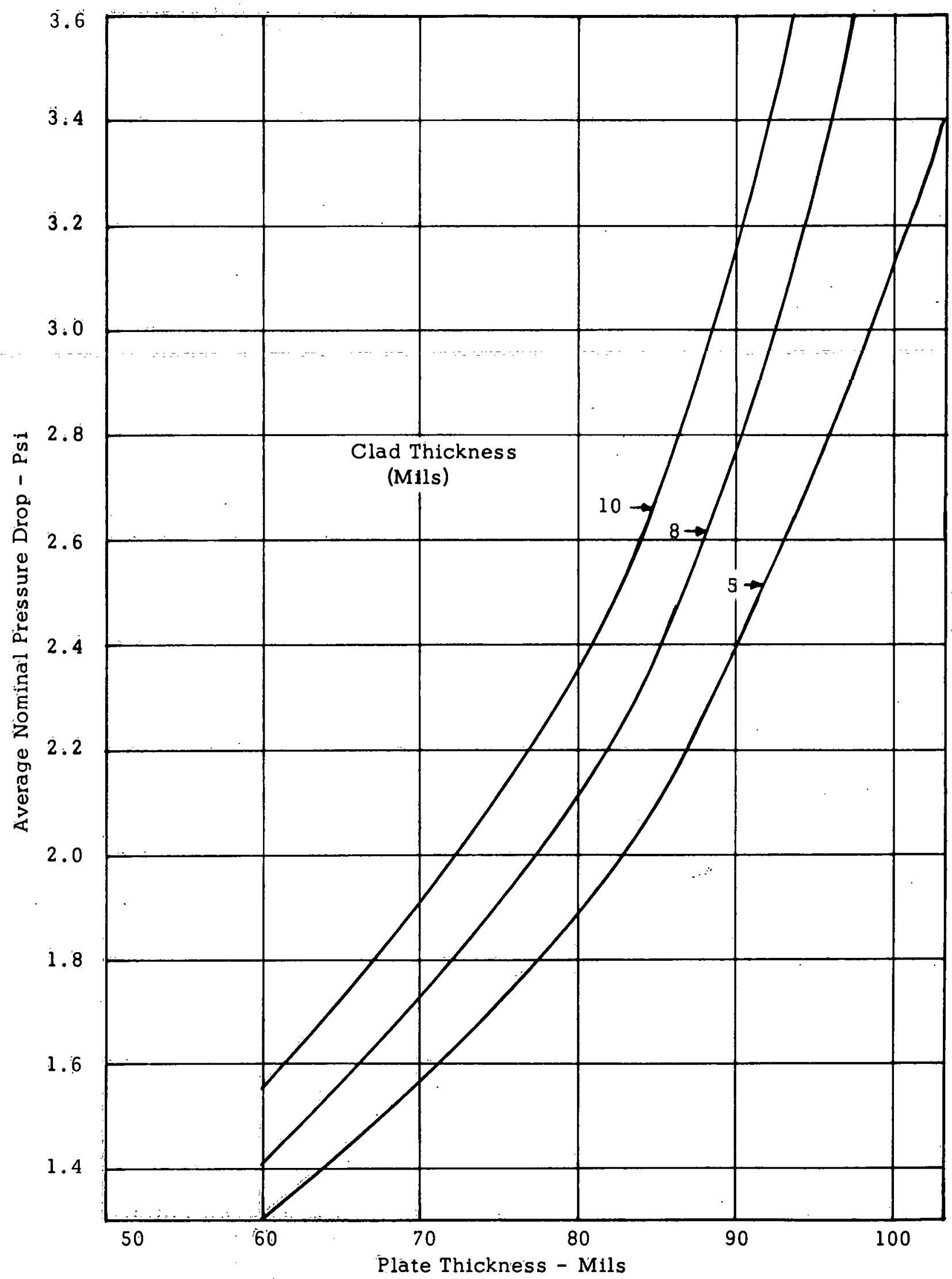

Figure 19. Average Pressure Drop Vs. Plate Thickness - SM-1A Type 5 Core $20 \mathrm{MW}$ 


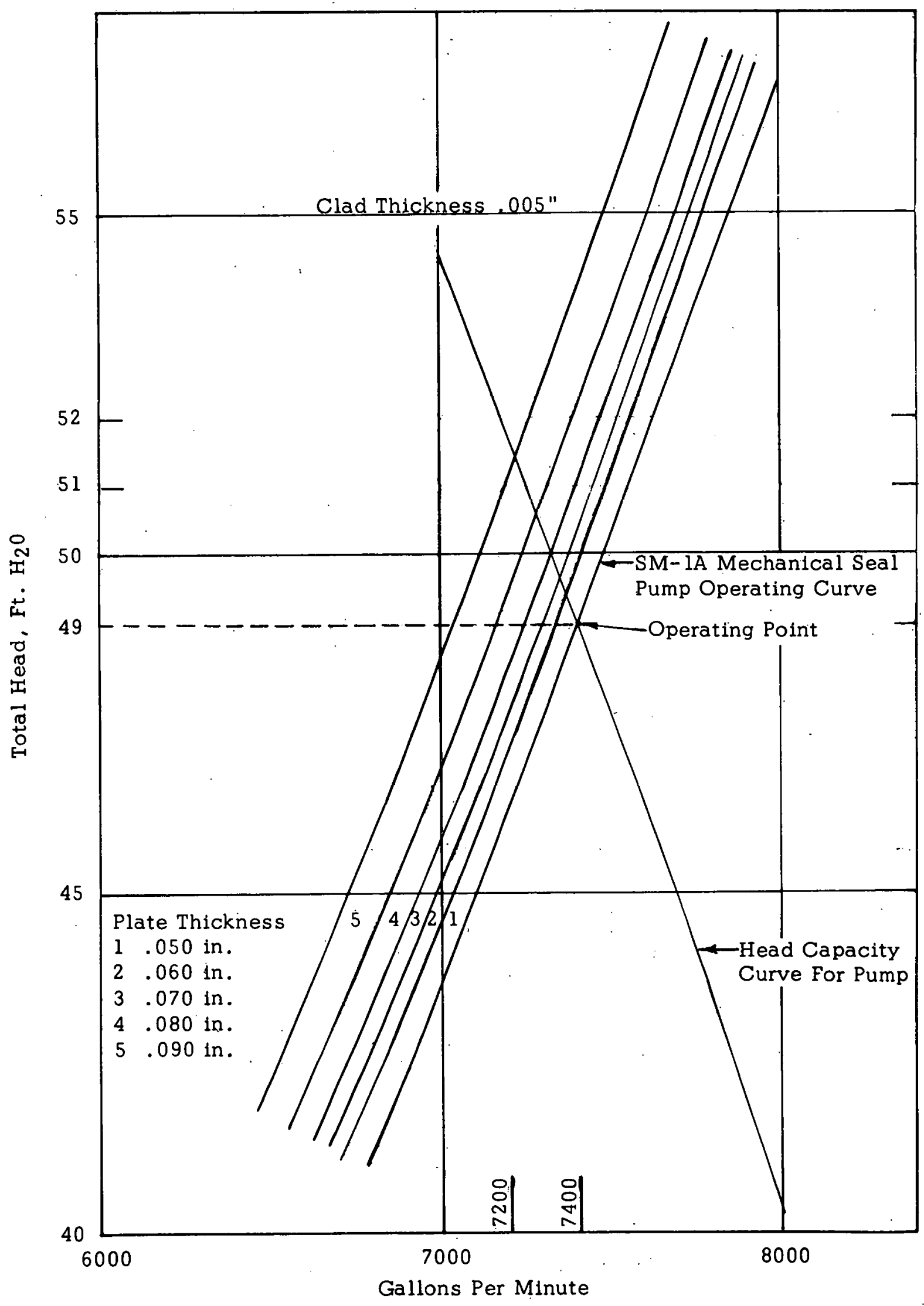

Figure 20. Type 5 Core Pump Operating Curves for SM-1A Mechanical Seal Pump 
1. The fuel plate is a three-layer flat infinite plate symmetric about the midplane. The central layer is a homogeneous fuel-bearing region called the meat. The outer layers are the clad and are identical to one another.

2. Heat is generated in the meat at a uniform volumetric rate.

3. The material properties of the meat and the clad are constant but not necessarily the same in the two phases.

4. The outer surfaces of the clad are kept at a constant temperature which may be taken as zero without loss of generality.

3. 'l'he only temperature variation is that through the thickness, i.e. variations across the width and longitudinally are neglected.

6. Thermal stresses are induced which act in the direction of the plane of the plate. These stresses vary through the thickness of the plate.

7. The plate is in a state of bi-axial plane strain. Every plane section perpendicular to the plane of the plate remains plane. Strain is constant throughout the plate.

8. There is no bending or buckling of the plate.

The following symbols are used:

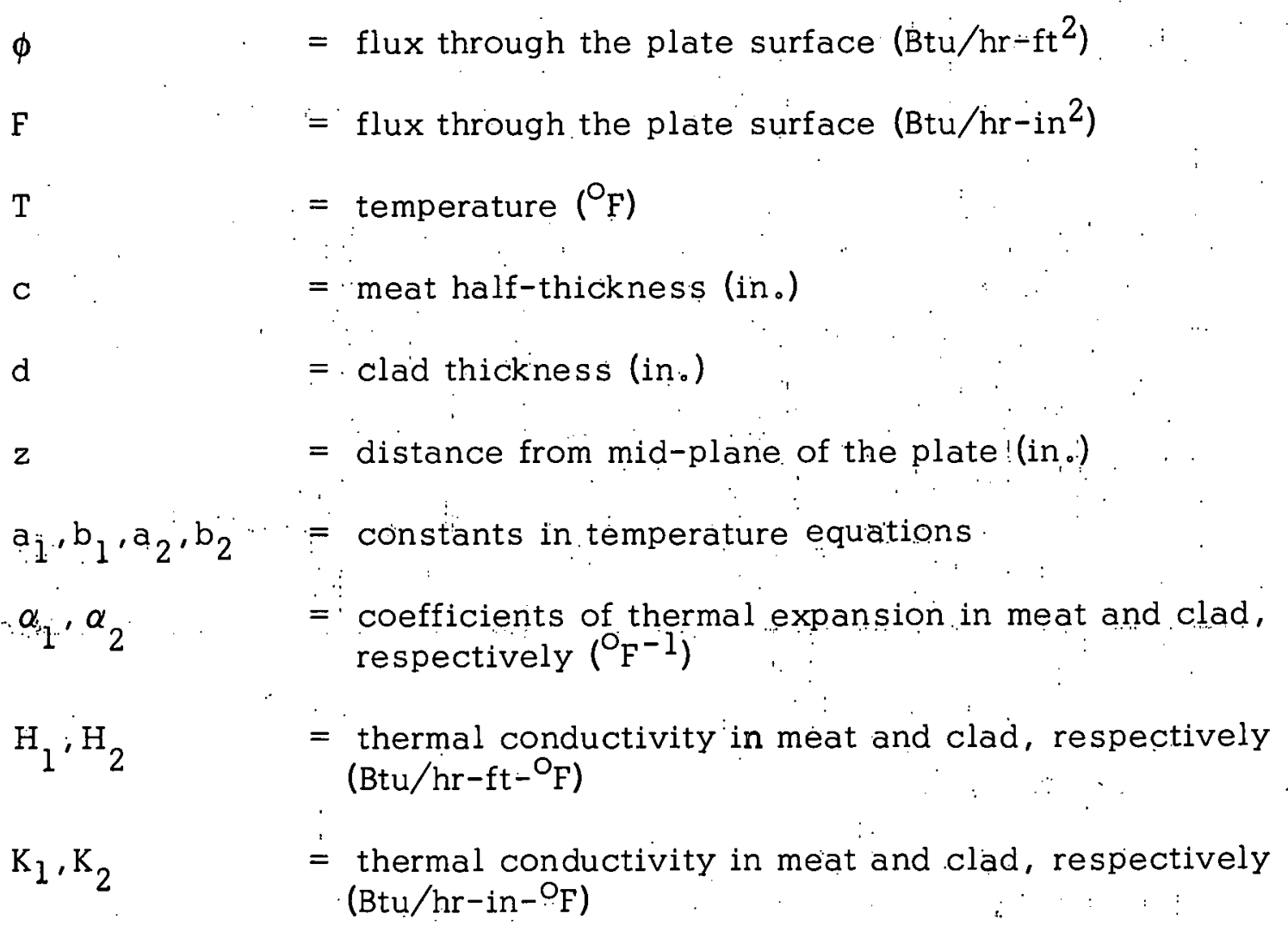




$$
\begin{array}{ll}
\stackrel{E}{E}, \dot{E}_{2} & =\begin{array}{c}
\text { modulus of elästicity in the meat and clad, respectively } \\
\left(\mathrm{lbs} / \mathrm{in}^{2}\right)
\end{array} \\
\nu_{1}, \dot{\nu}_{2} & =\text { Poisson's ratio in the meat and clad, respectively } \\
\epsilon & =\text { strain in the plate } \\
\ddot{\sigma} & =\text { stress in the plate }\left(\mathrm{lbs} / \mathrm{in}^{2}\right)
\end{array}
$$

The temperatures are found to be -

$$
\dot{\mathrm{T}}_{\mathrm{i}} \quad=\mathrm{a}_{i}-\mathrm{b}_{1} \mathrm{z}^{2}
$$

in the meat and -

$$
\mathrm{T}_{2} \quad=\mathrm{a}_{2}-\mathrm{b}_{2} \mathrm{z}
$$

in the clad where -

$$
\begin{aligned}
& a_{i}=\mathrm{F}\left(\mathrm{d} / \mathrm{K}_{2}+\mathrm{c}^{\prime} / 2 \mathrm{~K}_{1}\right) \\
& \mathrm{b}_{1} \quad=\mathrm{F} / \mathrm{cK}_{1} \text {. } \\
& a_{2} \quad=F(c / 2+d) / K_{-2} \\
& \mathrm{~b}_{2}=\mathrm{F} / \mathrm{K}_{2}
\end{aligned}
$$

The strain is

$$
\epsilon=\frac{F\left[\left(\alpha_{1}\left(2 c^{2} \dot{\gamma}+6 c d\right)+3 p \alpha_{2} d^{2}\right)\right]}{6 K_{2}(c+p d)}
$$

where

$$
\gamma=\mathrm{K}_{2} / \mathrm{K}_{1} ; \rho=\mathrm{E}_{2}\left(1-\nu_{1}\right) / \mathrm{E}_{1}\left(\mathrm{1}-\nu_{2}\right)
$$

The thermal stresses vary with $z$ and are -

$$
\sigma_{1}=\left[\left(E_{1} /\left(1-\nu_{1}\right)\right]\left(\epsilon-\alpha_{1} \dot{T}_{1}\right)\right.
$$

and

$$
\sigma_{2}=\left(E_{2} /\left(1-\nu_{2}\right) \quad\left(\epsilon-\alpha_{2} T_{2}\right)\right.
$$

in the méat and clàd, respectively.

The above system of stress equations for an infinite fuel plate were programmed for the IBM 650 . Figure 21 shows the variation of stresses in a 70 -mil fuel plate with 7-mil clad. 


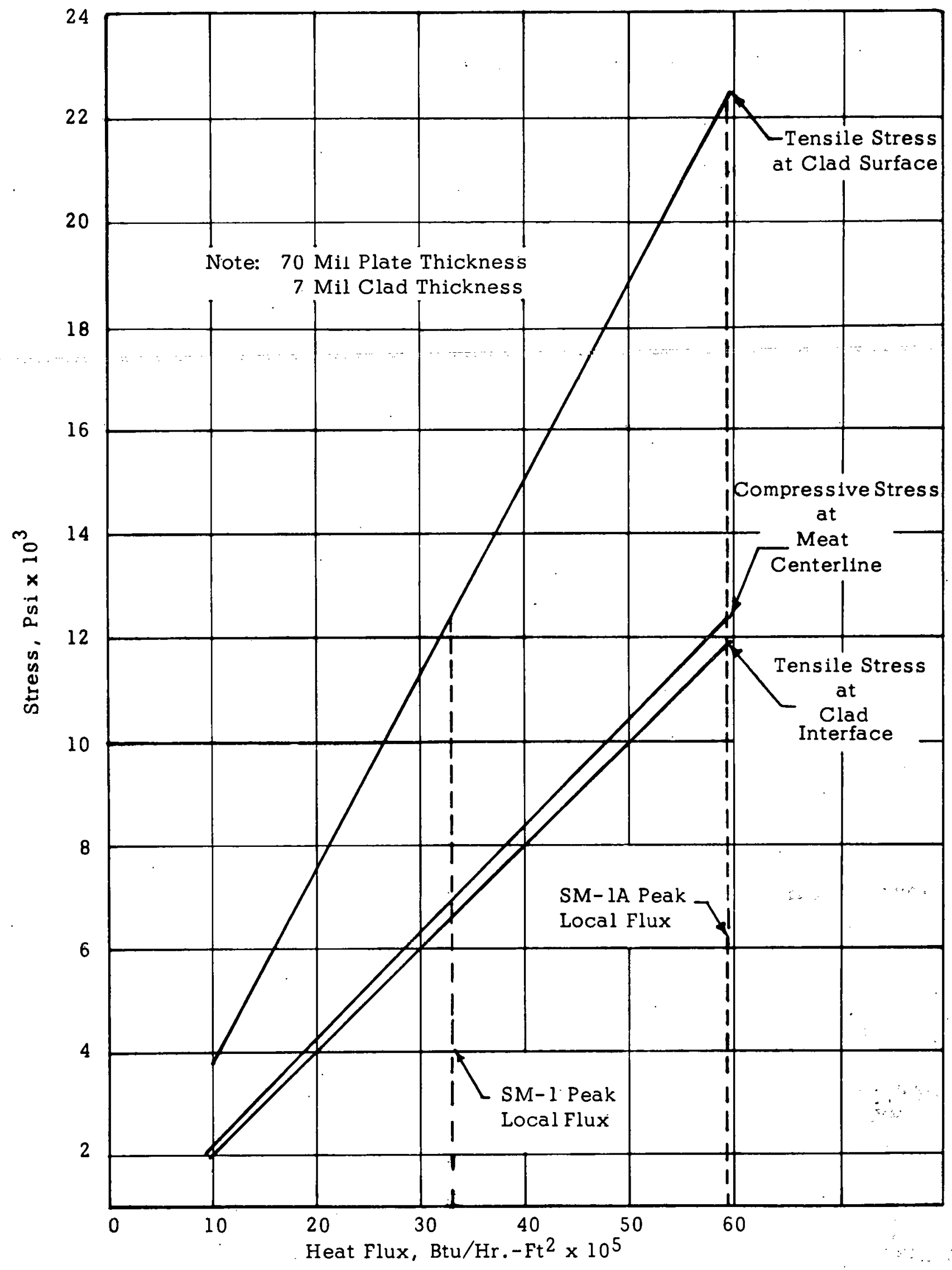

Figure 21. Type 5 Cores Thermal Stress Vs. Heat Flux 


\subsubsection{Stress Induced by Side Plate Restraint}

An analysis was performed to determine: if the allowable design stresses within the plates have been exceeded due to side plate restraint. The average thermal stress has been evaluated in a hot channel at the axial location where the severest temperature gradient and induced thermal stress exists. A correlation was developed in reference $(23)$ in which the average compressive stress in the meat is

where

$$
\delta_{\mathrm{m}}^{\therefore}=\frac{-\overline{\mathrm{E}} \bar{\alpha}_{\mathrm{m}}\left[\left(\mathrm{T}_{\mathrm{m}}-\mathrm{T}_{\mathrm{D}}\right)-\frac{\bar{\alpha}_{\mathrm{D}}}{\bar{\alpha}_{\mathrm{M}}}\left(\overline{\mathrm{T}}_{\mathrm{D}}-\mathrm{T}_{\mathrm{O}}\right)\right]}{\left(\frac{\overline{\mathrm{E}}_{\mathrm{D}}}{\mathrm{E}}+\frac{A_{\mathrm{m}}}{\mathrm{A}_{\mathrm{D}}} \cdot \frac{\overline{\mathrm{E}}_{\mathrm{m}}}{\mathrm{E}}\right)(1-\nu)}
$$

$\delta_{\mathrm{m}}=$ average meat compressive stress - psi

$\bar{\alpha}_{\mathrm{m}}:=$ average meat thermal coefficient of expansion - in,o/in。 ${ }^{\mathrm{F}}$

$\bar{\alpha}_{D}=$ average dead edge thermal coefficient of expansion - in。 $/$ in. ${ }^{\circ} F$

$\overline{\mathrm{E}}=\sqrt{\overline{\mathrm{E}_{\mathrm{m}} \cdot \overline{\overline{\mathrm{E}}}_{\mathrm{D}}}}$.

$\bar{E}_{\mathrm{m}} \quad=$ average meat modulus of elasticity - psi

$\overline{\mathrm{E}}_{\mathrm{D}}=$ average dead edge modulus of elasticity - pși

$\mathrm{A}_{\mathrm{m}}=$ area of the meat $-\mathrm{in}^{2}$

$A_{D}=$ area of the dead edge - in: $^{2}$

$\overline{\mathrm{T}}_{\mathrm{m}}=$ average meat temperature $-{ }^{\circ} \mathrm{F}$

$\overline{\mathrm{T}}_{\mathrm{D}}=$ average dead edge temperature $-{ }^{\circ} \mathrm{F}$

$\mathrm{T}_{\mathrm{O}}{ }^{\prime}=$ initial coolant temperature $-{ }^{\circ} \mathrm{F}$

$\nu \quad=$ Poisson's ratio

For element position 31 in the SM-1-core

$$
\begin{aligned}
& \overline{\mathrm{T}}_{\mathrm{D}}=501.4^{\circ} \mathrm{F} \\
& \overline{\mathrm{T}}_{\mathrm{m}}=608.3^{\circ} \mathrm{F} \\
& \mathrm{T}_{\mathrm{O}}=70^{\circ} \mathrm{F}
\end{aligned}
$$




$$
\begin{aligned}
& \overline{\bar{E}}=25.67 \times 10^{6} \mathrm{psi} \\
& \bar{E}_{\mathrm{m}}=25.10 \times 10^{6} \mathrm{psi} \\
& \overline{\mathrm{E}}_{\mathrm{D}}=25.20 \times 10^{6} \mathrm{psi} \\
& \bar{\alpha}_{\mathrm{m}}=9.62 \times 10^{-6} \mathrm{in.} / \mathrm{in} \cdot{ }^{\circ} \mathrm{F} \\
& \bar{\alpha}_{\mathrm{D}}=9.49 \times 10^{-6} \mathrm{in.} / \mathrm{in}{ }^{\circ} \mathrm{F}
\end{aligned}
$$

On substluting lii llie duvve equation and solving for $\delta_{m}$, the compressive otres 3 in the nieal was calculared to be $-8808 \mathrm{psi}$. This stress is additive to the thermal stresses described in Section $4,2.1$ so that it tends to reduce clad tension and increase clad compression.

\subsection{FUEL CYCLE COST STUDY}

A fuel cycle cost study was undertaken to determine the relative costs of various Type 5 core configurations. The study was performed for $50-80$ mil plate thicknesses, 5-10 mil clad thicknesses and 35, 37.5 and $40 \mathrm{w} / \mathrm{O} \mathrm{UO}_{2}$ in the matrix for a full 45 element core. An IBM 650 code, "Fuel Cost Program for the IBM 650" was used to expedite the analysis.(25) Use charges, erection, installation, maintenance and operating costs were excluded from the cost study。 "This program was designed to calculate reactor fuel costs for a range of fuel loadings. enrichments and energy release rates. The output is given in mills per kwhr and consists of core fabrication costs, fuel burnup costs, spent fuel reprocessing costs, and shipping costs.

Core fabrication costs include production of $\mathrm{U}_{2}$ from $\mathrm{UF}_{6}$ which are chemical processing costs and loss during processing, resulting in a total cost of $\mathrm{UO}_{2}$. Using a material cost per element; of $\$ 450$, a fabrication "cost of $\$ 6000$ per element. the total core fabrication costs were obtained.

Fuel burnup costs were calculated based on an initial worth of U-235 of $\$ 13,200 / \mathrm{kg}$. Plutonium credit was neglected in this analysis.

Reprocessing costs include total cost of producing $\mathrm{UO}_{2}\left(\mathrm{NO}_{2}\right)_{2}$ and conversion of $\mathrm{UO}_{2}\left(\mathrm{NO}_{2}\right)_{2}$ to $\mathrm{UF}_{6}$.

All shipping charges are small as compared to the shipping of the spent fuel in its shielded cask to the reprocessing plant. Ocean shipping costs are $\$ 0.0048$ / ton-mile. Rail shipping costs are $\$ 0.08 /$ ton-mile。

Figure 22, 23, and 24 show the variation of fuel cycle cost with initial loading。 parametric in plate thickness, clad thickness and initial loading. These figures 


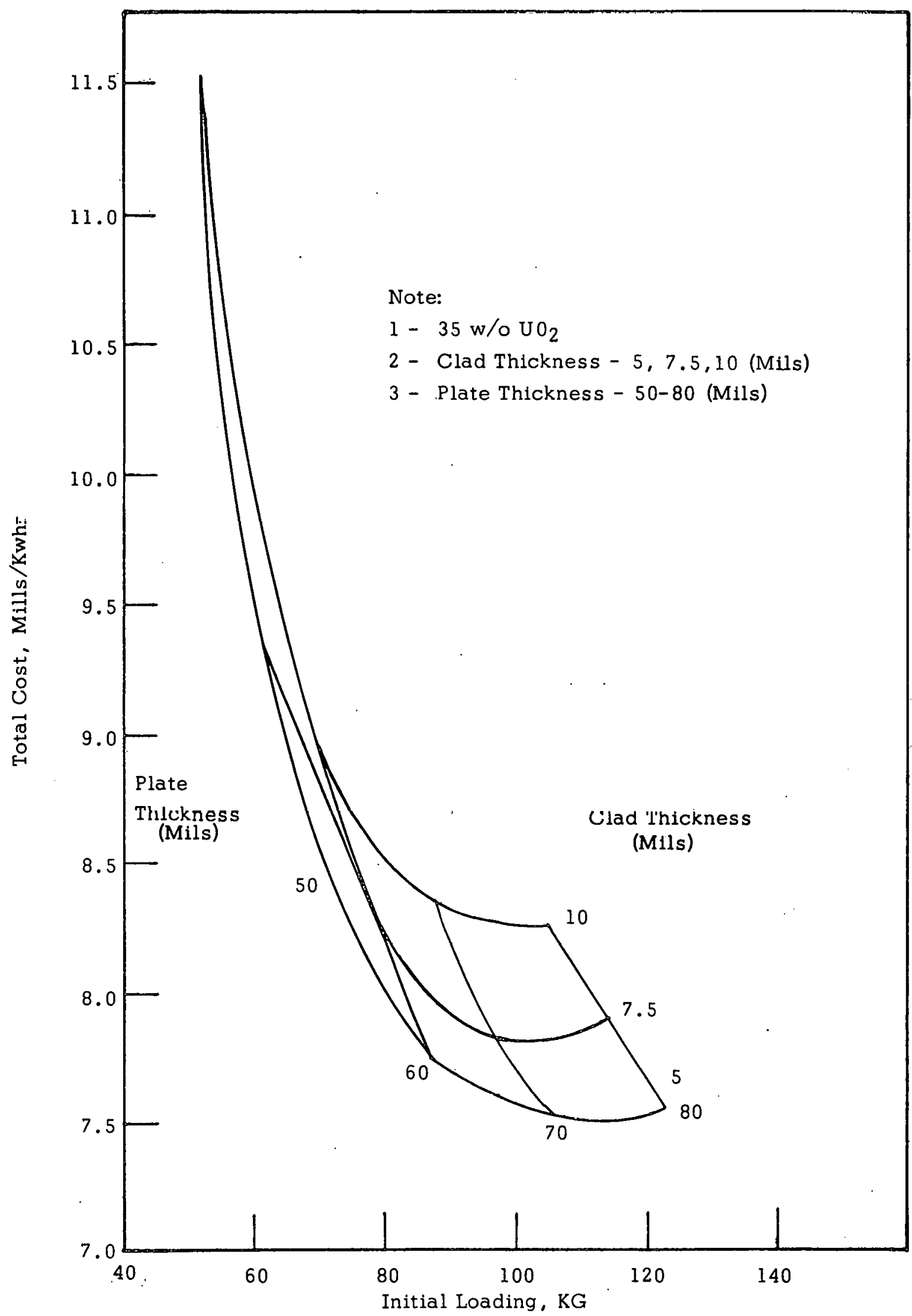

Figure 22. Total Cost Vs. Initial Load for Type 5 Core (45 fuel elements) 


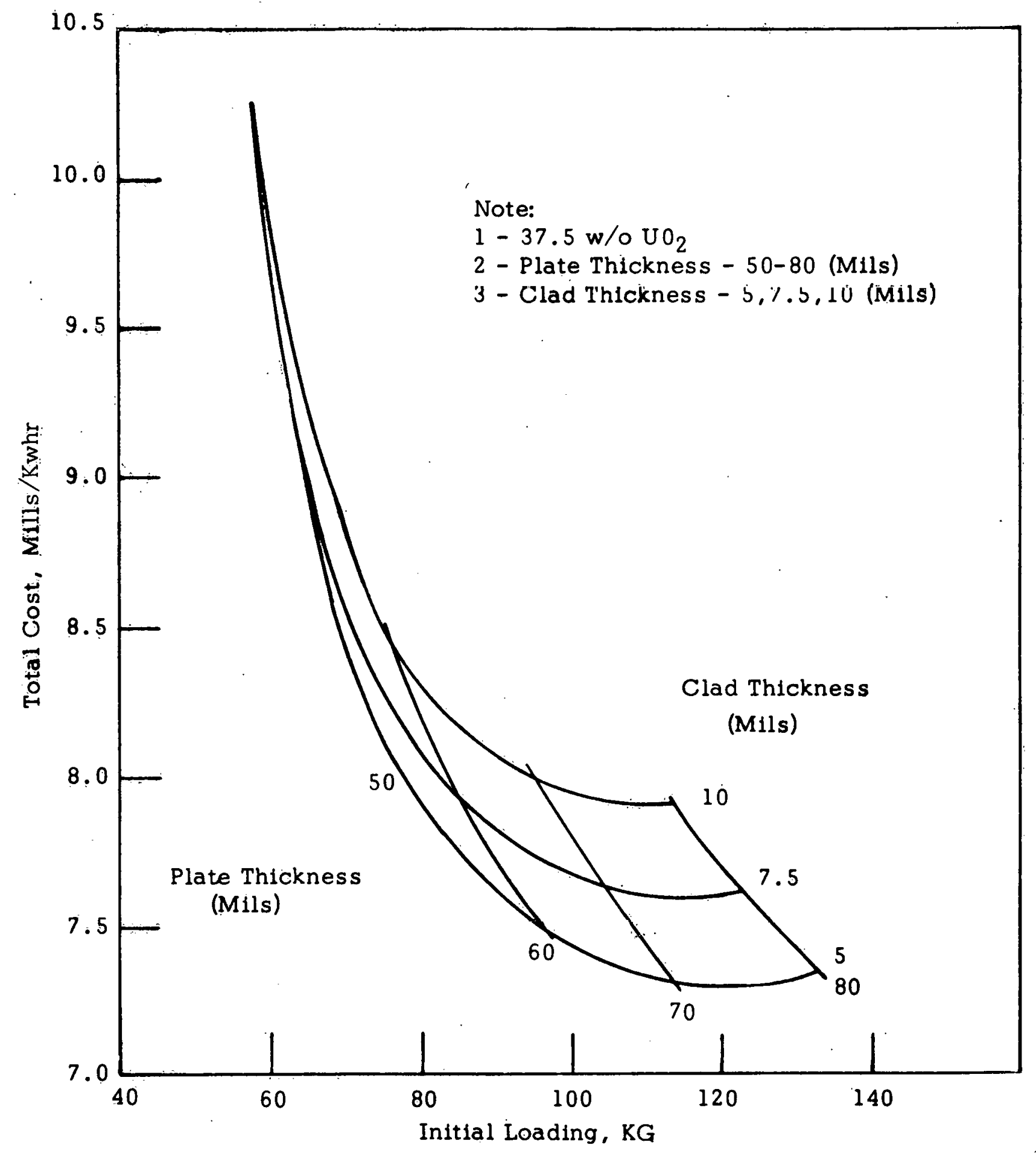

Figure 23. Total Cost Vs. Initial Loạd for Type 5 Core (45 fuel elements) 


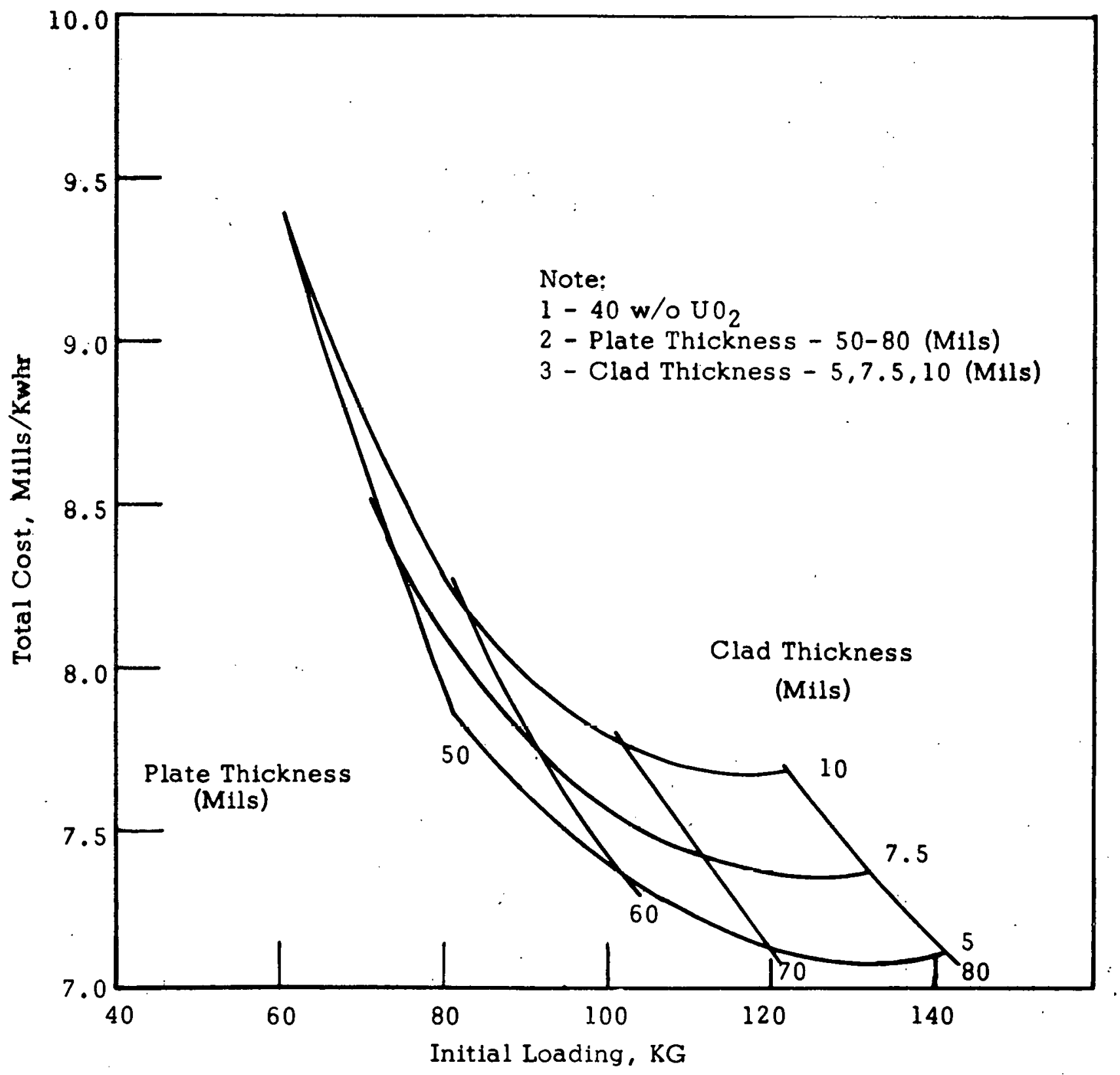

Figure 24. Total Cost Vs. Initial Load for Type 5 Core (45 fuel elements) 
show the strong dependency of total fuel cycle costs on initial core loading For a: $37.5 \mathrm{w} / 0$ matrix, the total cost: for a 50-mil plate $(0.010 \mathrm{mil}$ clad) is: 10.25 mills/kwhr, 60-mil plate, 8.45 mills/kwhr, 70-mil plate, $8.01 \mathrm{mills} / \mathrm{kwhr}$ and an $80-\mathrm{mil}$ plate, $7.91 \mathrm{mills} / \mathrm{kwhr}$. Energy release rates for these configurations are 50.5 MWYR, 74.8 MWYR, 89.15 MWYR, and 97.5 MWYR, respectively。' The results of this fuel cost study indicate lower costs for all increases: in core life. This philosophy will be the basis: for final selection of the reference design. 


\section{THIS PAGE}

WAS INTENTIONALLY

LEFT BLANK 


\subsection{SELECTION OF REFERENCE DESIGN NO. I}

\section{I I'HERMAL CRITERIA}

The fundamental thermal criteria which is used in the reference design selection is the minimum DNBR. A level of 1.5 has been established as the minimum. design point. Since only steady state analyses have been performed for the survey, a minimum DNBR level of 2.0 is specified to conservatively allow for some potential dron diring a trancicnt. No lucal nucleate or bulk boiling is permitted under any conditions in the nominal chamels.

In the SM-1 and SM-1A core, the hot channel analysis has shown that the minimum DNBR's exceed 2。0. for the 70-mil plate, 7-mil clad. Thicker plates with DNBR's below 2.0 were not considered. Local nucleate and bulk boiling exists. in the hot channels of the SM-I Core for heat fluxes above design conditions. Since this condition does not occur in the nominal channel and the inception of bulk boiling occurs above design conditions, a 70-mil plate, 7-mil clad meets the established thermal criteria at steady state. This criteria is also met in the SM-IA core.

The effects of a 70-mil plate core on the SM-1 overall loop pressure drop will be insignificant since only small variations in average channel pressure drop were noted. Larger variations in loop pressure drop were noted in the SM-1A。 However, since this increase in overall loop pressure drop is only $4 \%$, no adverse effects on primary loop performance are expected.

\subsection{NUCLEAR CRITERIA}

$\quad$ The reference design must meet the following nuclear design criteria: a. $3 \%$ reactivity startup margin at $440^{\circ} \mathrm{F}$ with equilibrium xenon, a one rod stuck criteria at most reactive time in life and a combination of plate thickness. clad thickness and loading that gives the largest energy release and minimum cost within metallurgical and thermal-hydraulic limitations.

The most favorable combination of energy release and total cost will be used to determine the Type 5 reference core. Maximum energy release and minimum total cost occur for maximum $\mathrm{w} / \mathrm{O} \mathrm{UO}_{2}$ in the matrix, minimum clad thickness, and maximum plate thickness considering the range 50-80 mils. Since both energy release and total cost are approximately constant for plate thicknesses between 70 and $80 \mathrm{mils}$, the choice of $70 \mathrm{mils}$ is a logical one. 
Due to metallurgical restrictions, the $\mathrm{w} / \mathrm{O} \mathrm{UO}_{2}$ is selected to be $38 \mathrm{w} / \mathrm{o}$ and clad thickness, ? mils. A minimum clad is desirable for economic reasons. The variation of core life with a 70-mil plate for 5, 7, and 10-mil clad thicknesses is 116,105 and 90 MWYR. The loss in core life with a 10-mil clad is too great to warrant its selection over a 5 or 7 -mil clad thickness. A thicker cladding would provide no additional protection against stress corrosion in an unfavorable environment which can exist from uncontrolled water chemistry. Since these cores have over 6 times the life of the cores with Type 1 or 2 fuel elements and over 3 times the life of cores with Type 3 elements (19) it was felt that the cladding should be increased from the 5 mils of Types 1,2 and 3 to 7 mills for Type 5 .

\subsection{THERMAL STRESS CRITERIA}

The maximum stress for the 70-mil plate, 7-mil clad occurs on the clad surface for the stress analysis under consideration in this report. Based on the peak local flux for the SM-1 and SM-1A, plate thicknesses above 80 mils exceed the yield strength of the clad material。 assuming it to be 347 stainless steel. Therefore, a 70-mil plate is a suitable choice from a stress standpoint.

\subsection{ECONOMIC CRIIERIA}

Economic studies have indicated important gains in core life and relatively - lower fuel costs for 70-80 mil plates. Smaller plates show shorter lifetimes and higher fuel costs. The selection of the 70-mil plate, 7-mil clad is logical tor obtaining maximum energy for a core with the minimum fuel cycle cost.

\subsection{NUCLEAR AND THERMAL DESIGN DATA}

The data resulting from the preliminary nuclear and thermal calculations performed on Type 5 cores are listed in Tables 4 and 5. 
TABLE 5

NUCLEAR CHARACTERISTICS OF TYPE 5

REF ERENCE DESIGN IN SM-1 ARRAY

(38 EIXED PLUS 7 CONTROL FUEL ELEMENTS)

\section{Characteristic}

Startup Margin at $440^{\circ} \mathrm{F} \mathrm{Eq}$. Xe

Initial U-235 Loading

$\therefore$ Initial B-10 Loading

$\mathrm{W} / \mathrm{O} \mathrm{UO}_{2}$ in Matrix

W/o BNat in Matrix

Metal-to-Water Volume Ratio

Energy Release

Average Fuel Burnup Fraction

Maximum Reactivity at $68^{\circ} \mathrm{F}$; No Xe

Temperature Defect

Worth of B-10 at Start-of-Life
Units

$\% \rho$

$\mathrm{kg}$

$g m$

$\%$

$\%$

MWYR

108

$\% \rho$

$\% \rho$

$\% \rho / g m$
0.41

0.77

0.50

12.4

3.4

Value

3

108

260

38

0.052

NOTE: Nuclear characteristics of Type 5 reference design in SM-1A array are identical to those for $S M-1$, except that the energy release. is slightly reduced ( $\cong$ I05.MWYR). 
TAPLE 6

PREIMMNARY THERMAI AND HYDRAU LIC DESIGN DATA FOR TYPE 5 CORES

Thermal Design Data

A. SM-1 Type 5 Core

Reactor thermal power

Maximum bulk water temperature

Maximum plate surface temperature

Maximum meat temperature

Effective core heat transfer area

Average core heat flux

Maximum core heat flux

Minimum DNBR' (steady state)

$\begin{array}{lc}\mathrm{Mw} & 10.77 \\ \mathrm{O}_{\mathrm{F}} & 565.2 \\ \mathrm{OF}_{\mathrm{F}} & 576.8 \\ \mathrm{O}_{\mathrm{F}} & 644.5 \\ \mathrm{ft}^{2} & 580.0 \\ \mathrm{Etu} / \mathrm{hr}^{2} \mathrm{ft}^{2} & 65.596 \\ \mathrm{Btu} / \mathrm{hr}^{2}-\mathrm{tt}^{2} & 323.234 \\ & 4.1\end{array}$

B. SM-1A Type 5 Core

Reactor thermal power

Maximum bulk water temperature

Maximum plate surface temperature

Maximum meat temperature

Effective core heat transfer area

Average core heat flux

Maximum core heat flux

Minimum DNBR (steady state)

$\begin{array}{lr}\mathrm{Mw} & 20.2 \\ \mathrm{O}_{\mathrm{F}} & 485.4 \\ \mathrm{O}_{\mathrm{F}} & 577.4 \\ \mathrm{O}_{\mathrm{F}} & 698.1 \\ \mathrm{ft}^{2} & 580.0 \\ \mathrm{Btu} / \mathrm{hr}-\mathrm{ft}^{2} & 121.748 \\ \mathrm{Btu} / \mathrm{hr}_{\mathrm{ftt}} \mathrm{ft}^{2} & 597.733 \\ : \quad: & 2.4\end{array}$

\section{Hydraulic Design Data}

A. SM-1 Type 5 Core

Primary system pressure

Nominal channel mass flow

Hot channel mass flow

Hot channel pressure drop

$\begin{array}{lr}\mathrm{psia} & 1200 \\ \mathrm{lb} / \mathrm{hr}-\mathrm{ft}^{2} \times 10^{6} & 0.812 \\ \mathrm{lb} / \mathrm{hr}-\mathrm{ft}^{2} \times 10^{6} & 0.558 \\ \mathrm{ft}-\mathrm{H}_{2} \mathrm{O} & 0.810\end{array}$

B. SM-1A Type 5 Core

Primary system pressure

Nominal channel mass flow

psia

1200

Hot channel mass flow

$1 \mathrm{~b} / \mathrm{hr}-\mathrm{ft}^{2} \times 10^{6}$

1.91

Hot channel pressure drop

$\mathrm{lb} / \mathrm{hr}-\mathrm{ft}^{2} \times 10^{5}$

1.77

$\mathrm{ft}-\mathrm{H}_{2} \mathrm{O}$

2.14 


\subsection{NUCLEAR ANALYSIS FOR SMALL-SIZE CORE STUDY}

A preliminary study was performed to determine the feasibility of a smallsize core employing the Type 5 reference fuel elements (70-mil plate, 7-mil clad, and $38 \mathrm{w} / \mathrm{O} \mathrm{UO}_{2}$ ) for various initial B-10 loadings.(22) The results, giving initial excess reactivity as a function of B-10 loading are displayed in Fig. 25 for $440^{\circ} \mathrm{F}$, using all fixed fuel elements, and no xenon. It is observed that the $3 \times 3$ core (no B-10) is subcritical, while the $4 \times 4$ core (no $\mathrm{B}-\mathrm{I0}$ ) has an excess reactivity of $6 \% \rho$. However, the negative reactivity worth of several control fuel elements substituted for fixed elements, in addition to equilibrium xenon, will reduce the initial reactivity. The $5 \times 5$ and $6 \times 6$ cores indicate that they would probably yield significant energy releases. In addition, it is observed that the use of a beryllium reflector in place of water considerably increases the reactivity of the $3 \times 3$ core, and offers an energy release of approximately 18 MWYR。 The small size ( 9 in。 $x 9$ in。 $x 22$ in。) and high energy release should open up a number of interesting applications for a $3 \times 3$ core utilizing Type 5 fuel elements. 


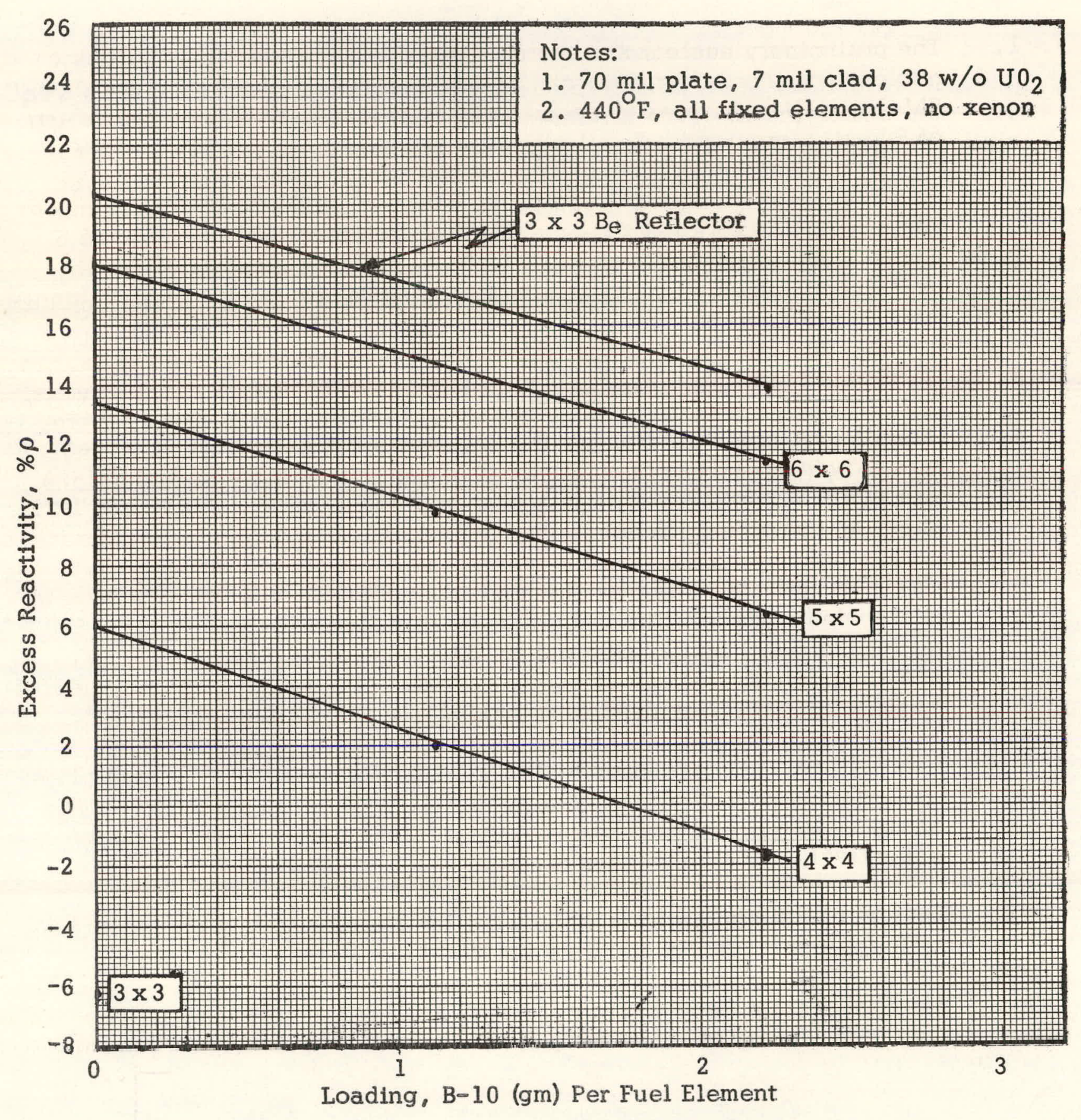

Figure 25. Small-Size Type 5 Reference Design 


\subsection{CONCLUSIONS}

1. The preliminary nuclear and thermal analysis indicates that the basic nuclear and thermal criteria can be met and that it is feasible for the SM-I and SM-IA cores to operate safely with a Type 5. core consisting of 70-mil plates and a 7-mil clad.

2. Energy:release, maximum reactivity, worth of B-10, power distributions and peaking factors have: been analytically determined for the Type 5 Cores. The energy release rates were as mucha's a factor of seven over Type: I cores, thereby indicating potential for the future development of replacement cores .

3. DNBR was practically invariant with plate thickness.

4. Overall loop pressure drop for the SM-1 was insignificantly affected with a Type 5 70-mil plate. Overall loop pressure drop for the SM-1A was: increased by $4 \%$. This increase: in pressure drop should have: little effect on pump performance.

5. Maximum thermal stress for the analysis under consideration occurred on the clad surface. The magnitude of this tensile stress was 12,500 psi for the SM-1 and 22,300 psi for SM-1A at peak. local flux for the reference design. These stresses are safely below the yield" strength of the material presently used in the SM-1 and SM-1A fuel plates.

6. Core fabrication costs amounted to $0.58 \mathrm{mills} / \mathrm{kw}-\mathrm{hr}$ for a 70 -mil plate 7-mil clad core in the SM-1 plant. This total cost is much lower than the SM-I Core I and Core III which were 2.54 and 1.35 mills $/ \mathrm{kw}-\mathrm{hr}$ respectively。 (See Appendix B。)

7. The use of the synthetic technique for the nuclear survey proved to be useful and sufficiently accurate: for this type of analysis.

8. The small size core ( 9 in。 $\times 9$. in $\times 22$ in。 ) with high energy release should open up a number of interesting applications for Type 5 fuel elements. 


\section{THIS PAGE}

WAS INTENTIONALLY

LEFT BLANK 


\subsection{RECOMMENDATIONS AND RUTURE? WORK}

I. Critical experiments are needed to supply correction factors to be used.in determining power peaking. factors and verifying nuclear models. More accurate nuclear calculations should be performed to confirm the preliminary nuclear results.

2. New applicable computer codes are needed for more realistic thermal. analyses of hot channels in the bulk boiling regime, such as TITE: (24)

3. A complete: review of the mechanical design of a 70-mil plate element should be made.

4. A transient analysis and plant kinetic study should be performed on a 70-mil plate SM-1 core 。

5. A water chemistry program should be initiated to resolve the problem of long. term exposure of fuel plate material to primary coolant.

6. Preliminary analysis on the small-size Type 5 core indicates sufficient promise from the standpoint of energy release for future, more detailed, investigations: 
THIS PAGE

WAS INTENTIONALLY

LEFT BLANK 


\subsection{REFERENCES}

1. Fried, B.E., et al, "Analysis of Reactivity, Burnup; and Lifetime for the SM-2 Reference Core," AP Note-366, Alco Products, Inc。, July 20, 1961.

2. Oggerino, JoP. " Power Distributions for Type 3 Replacement Cores for SM-I; SM-1A and PM-2A;" APAE-119, to be published June 1962 .

3. Rosen, S.S., "Hazards Summary Report for the Army Package Power Keactor, SM-1,"APAL-2, Kevision 1, May 1960。

4. Carr, B.P., Project Engineer, "Hazards Summary Report for SM-1A," APAE-13 Supplement 2, July 1, 1960 。

5. Hoover, H.L. , "SM-2 Core and Vessel Design Analysis " APAE-69, Volume III of III, March 3, 1961 .

6. Personal Communication, E.C. Edgar, Alco Products, Inc., Metallurgy Division.

7. Bobe, P.E., et al, "Interim Report of Nuclear Analysis Performed on SM-2 Core and Vessel, September 1, 1958-December 31, 1959,". APAENo.65. May 27, 1960.

8. Hellens, R.L., "Multigroup Fourier Transform Calculation, Description of the MUFT-III Code," WAPD-TM-4, July 1956.

9. Byrne, B.J.. " Analysis of Extended Zero Power Experiments on the Army Package Power Reactor, ZPE-2,"APAE-27, May 7, 1958.

10. Byrne, B.J.., and Caton, R.L., "Two-Dimensional P-3 Calculation for APPR-Type Fixed Fuel Elements," AP Note-96, Alco Products, Inc., February: 14, 1958 .

11. Lois, L。, et al, "Summary Report of Analysis of Physics Measurements Performed on SM-1 Core I, "APAE-103, March 30, 1962.

12. Bilodeaux, G.G. et al, "PDQ - An: IBM-704 Code to Solve the TwoDimensional Few Group Neutron Diffusion Equation, "WAPD-TM-70, August 1957.

13. Bobe, P.E., and Oby, P.V., "PROMPT-I: Preparation Routine for MUFT-III and P-3 Theory on the IBM-650, Program 50," AP Note-134。Alco Products, Inc. , April 7, 1959. 
14. Krase, J。M., and Cyl-Champlin, C., "Synthetic Experiment Design Technique in Reactor Analysis," APEX-303, November 30, 1956.

15. Blaine, R。A., and Watts, J.L。, "Radial Flux Flattening in the Organic Moderated Reactor Critical Assembly by Variable Fuel-To-Moderator Ratio," NAA-SR-5858, August 15, 1961.

16. Fairbanks, F。B., "Two-Group Multiregion Axial WINDOWSHADE Calculation on the IBM-650。" APAE Memo-88, March 29, 1957.

17. Weiss, S.H., "Summary Report of Physics Measurements on SM-I Core I," APAE-96, February 6, 1962。

18. Oby, P.V., "Modified Two-Group Multiregion Calculation Using the VALPROD Code for the IBM-650," AP Note 24 (Revised), Alco Products,Inc., August 14, 1957 。

19. Krause, R.S., "Single Element Flow Tests for Type 3 (SM-2) Fuel Elements in SM-1, SM-1A and PM-2A Cores, APAE Memo-297, November 27, 1961.

20. Pyle, R.S., "STDY-3 - A Program for the Thermal Analysis of a Pressurized Water Reactor During Steady State Operation," WAPD-TM-213, June: 1960 .

2I. Alco Products; Inc., "Fiscal Year 1962 Program Plan for Engineering Support and Development of Army: PWR Power Plants, "September 6, 1961.

22. Letter from $I$ 。 Adler, AEC-NYOO to $M \circ H$ 。 Dixon, Alco Products, Inc., dated October 4,1960 .

23. Hoover, H.L., Proj。Eng., "SM-2. Core and Vessel Design Analysis。 APAE-69, March 8, 1961.

24. Miller, R。I。 and Pyle。 R。S., "TITE - A Digital Program for the Prediction of Two-Dimensional Two-Phase Hydrodynamics," WAPD-TM-240, February, 1962。

25. Rosen, S.S., McElligott, P.E., "Fuel Cost Program for the IBM-650," APAE Memo-123, March 12, 1958.

26. Coombe, J.R. . editor, "Hazards Summary Report for a Prepackaged Nuclear Power Plant for an. Ice Cap Location (PM-2A)," APAE-49, Rev. 1。 July 14, 1961. 


\section{APPENDIX A DETAILED POWER ANALYSIS}

The preliminary calculations described in Section 3.8 were based on tworegion, one-dimensional diffusion theory ${ }^{*}$ To further verify the se approximate results, a two-dimensional few-group calculation, utilizing the PDQ-3 code (12) $^{2}$ was carried out. The results were obtained while this report was in publication. They showed that there is an increased radial power peak near the edge of the core (at a corner which has two sides exposed to the reflector). The PDQ local radial power peaking factor was calculated to be 5.03 , as compared to a local power peaking factor of 2.64 obtained from the one-dimensional calculations of The effect of this increased power peaking should definitely be further investigated. In addition, the revised maximum-to-average axial power peak was found to be: 1.87 , as compared to the preliminary peak of 1.81 。

* All the thermal analysis in this report was based on results given in Section $3 \div 8$ 。

**. A steady: state thermal analysis, using the IBM 704 Code STDY-3, was performed on the reference design utilizing this revised distribution. Element Position 27 in the SM-1 core resulted in the highest elemental flow-to-power ratio and was selected for analysis. The results from this analysis indicated for the SM-1 design condition of $10.77 \mathrm{Mw}$ :

$\frac{\operatorname{MaxT_{S}-O_{F}}}{577.4} \quad \frac{\text { Max } T_{m}-O_{F}}{700.0} \quad \frac{\text { Min DNBR }}{1.34} \quad \frac{\text { MaxQuality-\% }}{53}$

Local nucleate and bulk boiling occurred in the hot channel. The nominal channel indicated no local or bulk boiling. The criteria for a minimum DNBR of 2.0 was not met for steady state operation. This indicates that unsafe conditions prevail from a thermal standpoint within this core during steady state operation.

It would be possible to reduce the large radial power peaking occurring at the edge of the core by employment of a stainless steel skirt (approximately 0.5 in. thick) or substitution of stainless steel plates for fuel plates in the outer peripheral elements. Stainless steel, being a fairly good material for absorbing epithermal neutrons, would absorb a considerable portion of the neutrons reflected from the water reflector to the core o thereby preventing them from producing thermal fissions in the core. The energy release: would be somewhat reduced by approximately 15 to $20 \%$ 。 


\section{THIS PAGE}

\section{WAS INTENTIONALLY \\ LEFT BLANK}




\section{APPENDIX B}

COMPARATIVE CORE FABRICATION COSTS

I. Type I and 2 (26 w/o UO 2,30 -mil plate, 20-mil core, 15 MWYR life)

Fuel loading $=22.4: \mathrm{Kg} \mathrm{U}-235+25 \%=27.9 / .80=35 \mathrm{Kg} \mathrm{UO}_{2}$

(1) Conversion $\mathrm{UF}_{6}$ to $\mathrm{UO}_{2}=35 \times 2.2 \times \$ 450 / 1 \mathrm{~b}$

(2) Conversion loss

(3). Stainless steel $5000 \mathrm{ib} @$ \$3.60.1b

(4). Qualification and fabrication 45 fuel elements $+7 \cdot 1 \mathrm{bs}$ Sect:@ \$5000

(5) Lea se charge $4-3 / 4 \%$ on $\mathrm{UO}_{2}$ during production

(T)

Total

(Unit) $335.5 / 15=\underline{22.3}$ thousand dollars per MWYR

$=\underline{2.54}$ mills per kwhr

II. Type $3(25 \mathrm{w} / 0,40$-mil plate, 30-mil core, 32 MWYR life)

Fuel loading $=37.8 \mathrm{Kg} \mathrm{U}-235+.25 \%=48.4 / .80=\underline{60.5 \mathrm{Kg}: \mathrm{UO}_{2}}$

(1). Conversion $\mathrm{UF}_{6}$ to $\mathrm{UO}_{2}$

(2) Conversion loss

(3) Stainless steel

(4). Qualification and fabrication

(5) Lease charge during production

(T)

(Unit) $379.0 / 32=11.8$ : thousand dollars per MWYR

64,800

6,300

18,000

260,000

$\frac{29}{\$ 379}, 000$

\section{$=\underline{1.35}$ mills per $\mathrm{kwhr}$}

III. Type 5 ( $38 \mathrm{w} / \mathrm{O} \mathrm{UO} 2$ 70-mil plate, 56-mil core, 108 MWYR life)

Fuel loading $=108 \mathrm{Kg} \mathrm{U}-235+25 \%=135 / .80=168.8 \mathrm{Kg} \mathrm{UO}_{2}$

(1) Conversion $\mathrm{UF}_{6}$ to $\mathrm{UO}_{2}$

167,000

(2) Conversion loss

$21,8.00$

(3) Stainless steel

18,000

(4) Qualification and fabrication

260,000

(5) Lease charge during production

(T)

Total

(Unit) $550.2 / 108=5.01$ thousand dollars per MWYR

83,400

$\$ 550,200$ 